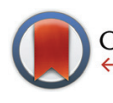

CrossMark \&lick for updates

Cite this: Dalton Trans., 2014, 43 15602

Received 4th July 2014, Accepted 13th August 2014

DOI: $10.1039 / c 4 d t 02025 a$

www.rsc.org/dalton

\title{
Towards a better understanding of magnetic exchange mediated by hydrogen bonds in $\mathrm{Mn}(\mathrm{III}) / \mathrm{Fe}(\mathrm{III})$ salen-type supramolecular dimers $\uparrow$
}

\author{
Ivan Nemec, Radovan Herchel, Tomáš Šilha and Zdeněk Trávníček*
}

\begin{abstract}
A thorough study of structural and magnetic properties was performed on a series of trinuclear and dinuclear $\mathrm{Mn}(\mathrm{III}) / \mathrm{Fe}(\mathrm{III})$ complexes consisting of $[\mathrm{M}(\mathrm{L} 4)(\mathrm{Solv})]^{+}$and $\left[\mathrm{Fe}(\mathrm{CN})_{5}(\mathrm{NO})\right]^{2-}$ moieties $(\mathrm{M}=\mathrm{Fe}(\mathrm{III})$ or $\mathrm{Mn}(\mathrm{III})$, Solv $=\mathrm{H}_{2} \mathrm{O}$ or $\mathrm{CH}_{3} \mathrm{OH}, L 4$ = tetradentate salen-type ligands), in which dominant magnetic exchange is mediated by $\mathrm{O}_{\mathrm{S}}-\mathrm{H} \ldots \mathrm{O}_{\mathrm{Ph}}$ hydrogen bonds in $[\mathrm{M}(\mathrm{L} 4)(\mathrm{Solv})]^{+} \ldots[\mathrm{M}(\mathrm{L} 4)(\mathrm{Solv})]^{+}$supramolecular dimers. As deduced from magnetic analysis involving the determination of zero-field splitting (ZFS) parameters for $\mathrm{Mn}(\mathrm{III})$ and Fe(III) ions, as well as from comprehensive DFT calculations and modelling, it may be concluded that the strength of the magnetic exchange is correlated with the number of hydrogen bonds and with the $\mathrm{O}_{\mathrm{Ph}} \cdots \mathrm{O}_{\mathrm{S}}$ distance between the phenolic oxygen atom of the salen-type ligand $\left(\mathrm{O}_{\mathrm{Ph}}\right)$ and the oxygen atom of the solvent molecule coordinated to the adjacent metal atom $\left(\mathrm{O}_{\mathrm{S}}\right)$.
\end{abstract}

\section{Introduction}

In recent years, a significant amount of research has been devoted to the study of molecular magnetic materials due to their potential applications as molecular switches or highdensity memory materials. ${ }^{1}$ There is a continuous effort to correlate the magnetic properties of such materials with their structures, in order to establish rational design methods for the preparation of molecule based magnetic materials. Most of the correlations reported thus far dealt with either the strength of the isotropic magnetic interactions, mediated through the covalent bonds between two paramagnetic metal atoms, ${ }^{2}$ or with the magnetic anisotropy defined by the zero-field splitting (ZFS) parameters - the prerequisite for observation of slowrelaxation of magnetisation. However, magnetic exchange mediated by non-covalent interactions such as hydrogen bonding or $\pi-\pi$ stacking of aromatic rings is emerging as another magnetic exchange coupling phenomenon, especially in the study of organic-based molecular magnets. This kind of exchange might also play an important role in coordination compounds with interesting magnetic properties, e.g. in mediating intrachain exchange interactions, thus giving rise to single-chain magnets, ${ }^{3}$ in magnetic sponges, ${ }^{4}$ in the occur-

Regional Centre of Advanced Technologies and Materials \& Department of Inorganic Chemistry, Faculty of Science, Palacký University, 17. listopadu 12, 77146 Olomouc, Czech Republic. E-mail: zdenek.travnicek@upol.cz; Fax: +420585 634954

$\dagger$ Electronic supplementary information (ESI) available. CCDC 998967-998971. For ESI and crystallographic data in CIF or other electronic format see DOI: 10.1039/c4dt02025a rence of slow-magnetic relaxation in polynuclear compounds ${ }^{5}$ or in simple paramagnetic compounds. ${ }^{6}$

Of particular importance amongst the magnetically interesting coordination compounds are the cyanido-bridged complexes (Prussian blue analogues and related compounds), ${ }^{7,8}$ which are of interest due to their structural and magnetic properties $^{9}$ and their potential use as optical devices and catalysts. ${ }^{10}$ A wide variety of cyanido complexes can be used as bridging units and these can be generally divided into two subgroups: (a) homoleptic cyanido complexes with the general formula $\left[\mathrm{M}(\mathrm{CN})_{x}\right]^{(x-m)-}(\mathrm{M}=$ transition metal, $x=$ number of cyanido ligands, $m=$ charge of $\mathrm{M}$ ) and (b) heteroleptic cyanido complexes $\left[\mathrm{M}(\mathrm{L})(\mathrm{CN})_{x}\right]^{(x+l-m)-}(\mathrm{L}=$ organic ligand different from $\mathrm{CN}, l=$ charge of $\mathrm{L}$ ). Such cyanidometallates can react with coordinatively unsaturated complexes (or labile complexes from a kinetic point of view) to form compounds which vary widely in their structures and magnetic properties.

The objective of the work reported herein was to prepare and characterize a series of trinuclear nitroprusside-bridged $\mathrm{Mn}(\mathrm{III}) / \mathrm{Fe}$ (III) complexes containing Schiff base ligands, ${ }^{11}$ or more specifically, salen-type ligands $\left(\mathrm{L}^{2-}=\right.$ salen $^{2-}=N, N^{\prime}-$ ethane-bis(salicylideneiminate) dianion; other abbreviations of the ligands used or mentioned in this work can be found in ref. 12), and therefore, such polynuclear salen-type compounds bridged by metallocyanates are briefly discussed below.

The cationic part in the presented complexes consists of the tetradentate salen-like dianionic ligand $\left(\mathrm{L}^{2-}\right)$ coordinated to the transition metal, thus creating the $[\mathrm{M}(\mathrm{L} 4)]^{(m-2)-}$ moiety, where the L4 ligand occupies the equatorial plane of the complex. Two axial positions are potentially available for 
coordination and therefore the $[\mathrm{M}(\mathrm{L} 4)]^{(m-2)-}$ moiety can be considered as a perfect building block for the preparation of low dimensional coordination compounds, and coordination polymers of various dimensions $(1 \mathrm{D}, 2 \mathrm{D}$ or $3 \mathrm{D})$ can also be prepared. In general, three basic structural types can be distinguished, where the $[\mathrm{M}(\mathrm{L} 4)]^{(m-2)-}$ moiety is coordinated by:

(A) One $\mathrm{N}$-cyanido ligand from the cyanidometallate, and a solvent molecule (most usually water or methanol) in the second axial position. The structure of the resulting complex is low-dimensional and polynuclear due to the terminal function of the solvent ligand (further abbreviated as Solv). However, the Solv molecules often extend the dimensionality of the crystal structure (usually to $1 \mathrm{D}$ arrays) by forming hydrogen bonding interactions with suitable acceptor atoms from neighbouring molecules (Scheme 1A, vide infra).

(B) Two $N$-cyanido ligands, each from different adjacent cyanidometallate molecules, and therefore the structure of the resulting complex is polymeric in most cases (Scheme 1B, vide infra).

(C) One $\mathrm{N}$-cyanido ligand from the cyanidometallate, and a phenolic oxygen atom from the adjacent $[\mathrm{M}(\mathrm{L} 4)]^{(m-2)-}$ molecule in the second axial position, thus forming a dimeric unit. It must be stressed that this kind of dimer is not unique for $\mathrm{Mn}^{\mathrm{III}}$ complexes and can also be found in other transition metal complexes (Co ${ }^{\mathrm{II} / \mathrm{III}},{ }^{13} \mathrm{Fe}^{\mathrm{III}},{ }^{14} \mathrm{Ru}^{\mathrm{III}},{ }^{15} \mathrm{Ti}^{\mathrm{III}},{ }^{16} \mathrm{Zn}^{\mathrm{II}}{ }^{17} \mathrm{Cu}^{\mathrm{II}}$ (ref. 18) and $\mathrm{Ni}^{\mathrm{II}},{ }^{19}$ Scheme $1 \mathrm{C}$ ).

A)
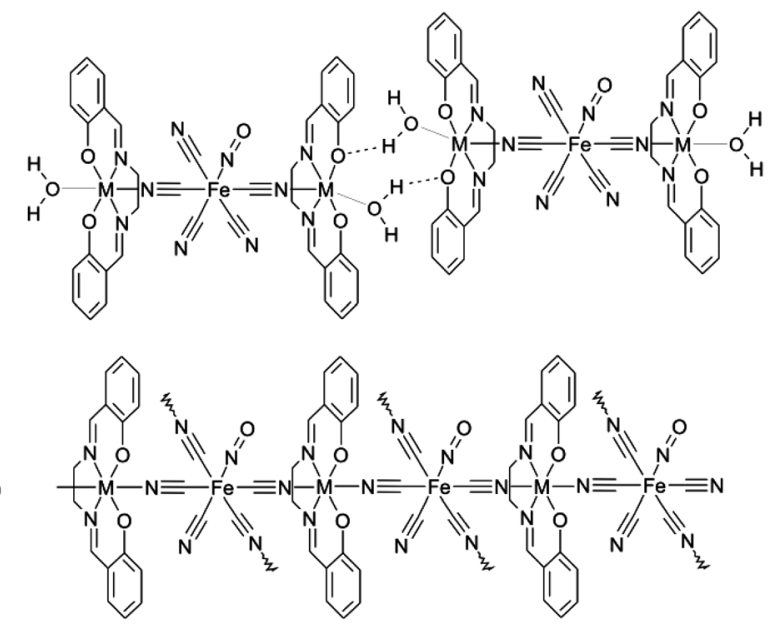

C)

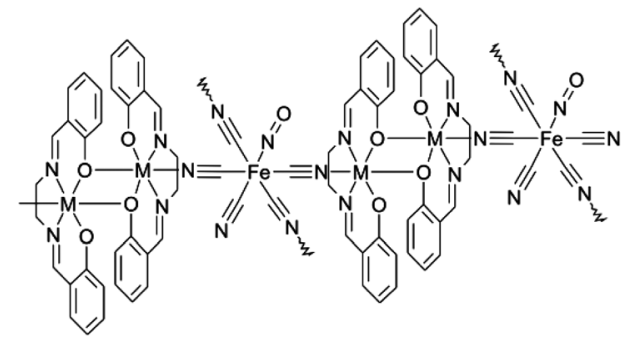

Scheme 1 Schematic representations of three structural types which result from reaction of the $[M(L 4)]^{(m-2)-}$ complexes with cyanidometallates.
In our previous work we have reported coordination compounds built from various $\left[\mathrm{Mn}^{\mathrm{III}}(\mathrm{L} 4)\right]^{+}$moieties bridged by $\left[\mathrm{Pt}(\mathrm{SCN})_{4}\right]^{2-}$ or $\left[\mathrm{Pt}(\mathrm{SCN})_{6}\right]^{2-}$ complex anions. ${ }^{20,21}$ Almost all of the prepared compounds were trinuclear with the general formula $\left[\{\mathrm{Mn}(\mathrm{L} 4)(\mathrm{Solv})\}_{2}\left\{\mu-\mathrm{Pt}(\mathrm{SCN})_{x}\right\}\right]$, where $x=4$ or 6 , and they thus belong to group (A). For those compounds it was shown that the exchange interactions mediated by the diamagnetic bridging anion are negligible and it was proven that the dominant magnetic exchange pathway occurs via non-covalent interactions, i.e. hydrogen bonding within the supramolecular dimer $[\mathrm{Mn}(\mathrm{L} 4)(\text { Solv })]^{+} \ldots[\mathrm{Mn}(\mathrm{L} 4)(\text { Solv })]^{+}$. Therefore, this kind of supramolecular system represents an ideal object of study for investigation of the magnetic exchange mediation through hydrogen bonding. Furthermore, it was observed that there is a significant difference in the strength of the magnetic exchange, depending on the type of Solv molecule bonded to the $\mathrm{Mn}^{\mathrm{III}}$ atom. In order to explore this phenomenon thoroughly we have studied another system with a diamagnetic bridging cyanidometallate, i.e. nitroprusside $\left[\mathrm{Fe}(\mathrm{CN})_{5}(\mathrm{NO})\right]^{2-}$, and furthermore, we have focused our attention not only on its $\mathrm{Mn}^{\mathrm{III}}$ complexes, but also on its $\mathrm{Fe}^{\mathrm{III}}$ ones.

From a literature survey on the above mentioned compounds it is apparent that the nitroprusside- $\left[\mathrm{M}^{\mathrm{III}}(\mathrm{L} 4)\right]^{+}$compounds $\left(\mathrm{M}^{\mathrm{III}}=\mathrm{Fe}^{\mathrm{III}}, \mathrm{Mn}^{\mathrm{III}}\right)$ which belong to group (A) (Scheme $\left.1 \mathrm{~A}\right)$ only include $\mathrm{Mn}^{\mathrm{III}}$ complexes (explanations of the following ligand abbreviations can be found in Scheme 2): $\left[\left\{\mathrm{Mn}(\mathrm{L} 4 \mathrm{i})\left(\mathrm{H}_{2} \mathrm{O}\right)\right\}_{2}\{\mu-\mathrm{Fe}-\right.$ $\left.\left.(\mathrm{CN})_{5}(\mathrm{NO})\right\}\right] \quad(7 \mathrm{a}),^{22}\left[\left\{\mathrm{Mn}(\mathrm{L} 4 \mathrm{~b})\left(\mathrm{H}_{2} \mathrm{O}\right)\right\}_{2}\left\{\mu-\mathrm{Fe}(\mathrm{CN})_{5}(\mathrm{NO})\right\}\right] \cdot 2 \mathrm{CH}_{3} \mathrm{OH}$ (7b), $\left[\left\{\mathrm{Mn}(\mathrm{L} 4 \mathrm{~m})\left(\mathrm{CH}_{3} \mathrm{OH}\right)\right\}_{2}\left\{\mu-\mathrm{Fe}(\mathrm{CN})_{5}(\mathrm{NO})\right\}\right] \quad(7 \mathrm{c}),{ }^{23 a}[\{\mathrm{Mn}(\mathrm{L} 4 \mathrm{k})-$ $\left.\left.\left(\mathrm{H}_{2} \mathrm{O}\right)\right\}_{2}\left\{\mu-\mathrm{Fe}(\mathrm{CN})_{5}(\mathrm{NO})\right\}\right] \cdot 2 \mathrm{H}_{2} \mathrm{O}(7 \mathbf{d})^{24}$ and $\left[\left\{\mathrm{Mn}(\mathrm{L} 4 \mathrm{l})\left(\mathrm{H}_{2} \mathrm{O}\right)\right\}_{2}\{\mu-\mathrm{Fe}-\right.$ $\left.\left.(\mathrm{CN})_{5}(\mathrm{NO})\right\}\right](7 \mathrm{e}) .^{25}$

The compounds which belong to group (B) are polymeric with two-dimensional crystal structures (Scheme 1B). In all reported cases the nitroprusside anion acts as a moiety which bridges four $\left[\mathrm{M}^{\mathrm{III}}(\mathrm{L} 4)\right]^{+}$entities, and thus creates grid-like sheets built from $\left[\{\mathrm{M}(\mathrm{L} 4)\}_{2}\left\{\mu_{4}-\mathrm{Fe}(\mathrm{CN})_{5} \mathrm{NO}\right\}\right]_{n}$ units. This group contains six coordination polymers: $\left[\{\mathrm{Mn}(\mathrm{L} 4 \mathrm{j})\}_{2}\left\{\mu_{4}-\mathrm{Fe}(\mathrm{CN})_{5}(\mathrm{NO})\right\}\right](\mathbf{7 f}){ }^{26}$ $\left[\{\mathrm{Mn}(\mathrm{L} 4 \mathrm{f})\}_{2}\left\{\mu_{4}-\mathrm{Fe}(\mathrm{CN})_{5}(\mathrm{NO})\right\}\right] \quad(7 \mathrm{~g}),{ }^{24} \quad\left[\{\mathrm{Fe}(\mathrm{L} 4 \mathrm{f})\}_{2}\left\{\mu_{4}-\mathrm{Fe}(\mathrm{CN})_{5^{-}}\right.\right.$ $(\mathrm{NO})\}]_{n}(\mathbf{7 h}),{ }^{27}\left[\{\mathrm{Fe}(\mathrm{L} 4 \mathrm{~g})\}_{2}\left\{\mu_{4}-\mathrm{Fe}(\mathrm{CN})_{5}(\mathrm{NO})\right\}\right](7 \mathbf{i}),{ }^{28}\left[\{\mathrm{Mn}(\mathrm{L} 4 \mathrm{f})\}_{2^{-}}\right.$

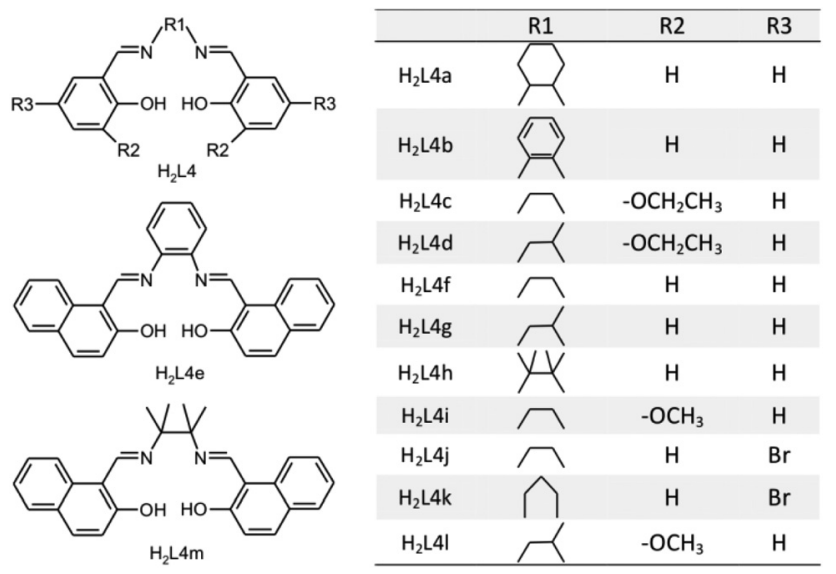

Scheme 2 Schematic representations of $\mathrm{H}_{2} \mathrm{~L} 4$ tetradentate Schiff base ligands referred to in this work and their abbreviations. 
$\left.\left\{\mu_{4}-\mathrm{Fe}(\mathrm{CN})_{5}(\mathrm{NO})\right\}\right] \cdot 2 \mathrm{H}_{2} \mathrm{O}(7 \mathbf{j})^{23 b}$ and $\left[\{\mathrm{Mn}(\mathrm{L} 4 \mathrm{f})\}_{2}\left\{\mu_{4}-\mathrm{Fe}(\mathrm{CN})_{5}(\mathrm{NO})\right\}\right] \cdot$ $2 \mathrm{H}_{2} \mathrm{O}(7 \mathbf{k}){ }^{23 a}$

Group (C), depicted in Scheme 1C, is represented by only one example: $\left[\{\mathrm{Mn}(\mathrm{L} 4 \mathrm{~h})\}_{2}\left\{\mu_{4}-\mathrm{Fe}(\mathrm{CN})_{5}(\mathrm{NO})\right\}\right](7 \mathrm{l}){ }^{24}$ This compound is polymeric with four $\left[\{\mathrm{Mn}(\mathrm{L} 4 \mathrm{~h})\}_{2}\right]^{2+}$ dimers bridged by one nitroprusside anion, thus creating a two-dimensional network.

In this article a great deal of attention is devoted to the study of seven novel trinuclear nitroprusside complexes with salentype Schiff base ligands and the general formula $\left[\left\{\mathrm{M}^{\mathrm{III}}(\mathrm{L} 4)-\right.\right.$ $\left.\left.\left(\mathrm{H}_{2} \mathrm{O}\right)\right\}_{2}\left\{\mu-\mathrm{Fe}(\mathrm{CN})_{5}(\mathrm{NO})\right\}\right] \cdot x \mathrm{CH}_{3} \mathrm{OH}, x=0$ or 1 and $\mathrm{M}=\mathrm{Fe}$ or $\mathrm{Mn}$.

The crystal structures of complexes $\left[\left\{\mathrm{Fe}(\mathrm{L} 4 \mathrm{~b})\left(\mathrm{H}_{2} \mathrm{O}\right)\right\}_{2}\{\mu\right.$-Fe$\left.\left.(\mathrm{CN})_{5}(\mathrm{NO})\right\}\right] \cdot 2 \mathrm{CH}_{3} \mathrm{OH} \quad(3 \mathbf{a}), \quad\left[\left\{\mathrm{Fe}(\mathrm{L} 4 \mathrm{c})\left(\mathrm{H}_{2} \mathrm{O}\right)\right\}_{2}\left\{\mu-\mathrm{Fe}(\mathrm{CN})_{5}(\mathrm{NO})\right\}\right]$ (4a), $\left[\left\{\mathrm{Mn}(\mathrm{L} 4 \mathrm{c})\left(\mathrm{H}_{2} \mathrm{O}\right)\right\}_{2}\left\{\mu-\mathrm{Fe}(\mathrm{CN})_{5}(\mathrm{NO})\right\}\right] \quad(4 \mathbf{b})$ and $[\{\mathrm{Fe}(\mathrm{L} 4 \mathrm{~d})-$

Table 1 Selected structural parameters for nitroprusside complexes. Bond lengths are given in $\AA$

\begin{tabular}{|c|c|c|c|c|c|}
\hline & $\mathrm{M}-\mathrm{N}_{\mathrm{im}}{ }^{a}$ & $\mathrm{M}-\mathrm{O}_{\mathrm{Ph}}{ }^{a}$ & $\mathrm{M}-\mathrm{N}_{\mathrm{CN}}$ & $\mathrm{M}-\mathrm{O}_{\mathrm{S}}$ & $\Sigma /^{b}$ \\
\hline $3 a$ & 2.109 & 1.896 & $2.151(2)$ & $2.0548(16)$ & 37.7 \\
\hline $4 a$ & 2.085 & 1.897 & $2.1512(14)$ & $2.1309(12)$ & 56.4 \\
\hline $4 b$ & 1.973 & 1.878 & $2.343(3)$ & $2.256(2)$ & 44.4 \\
\hline $5 a$ & 2.084 & 1.889 & $2.163(2)$ & $2.143(2)$ & 53.9 \\
\hline 6b mol1 & 1.962 & 1.882 & $2.245(3)$ & $2.292(2)$ & 22.4 \\
\hline $6 \mathbf{b} \mathrm{mol} 2$ & 1.953 & 1.868 & - & $\begin{array}{l}2.309(2) \\
2.256(2)\end{array}$ & 29.5 \\
\hline $7 a$ & 1.970 & 1.863 & $2.355(6)$ & $2.271(5)$ & 49.6 \\
\hline $7 \mathbf{b}$ & 1.986 & 1.872 & $2.304(6)$ & $2.223(5)$ & 27.2 \\
\hline $7 c$ & 1.962 & 1.881 & $2.288(4)$ & $2.358(3)$ & 53.8 \\
\hline $7 d$ & 2.036 & 1.900 & $2.263(6)$ & $2.224(5)$ & 35.4 \\
\hline $7 e$ & 1.981 & 1.880 & $2.394(2)$ & $2.258(2)$ & 46.3 \\
\hline $7 f$ & 1.989 & 1.863 & $2.378(2)$ & - & 54.1 \\
\hline $7 \mathrm{~g}$ & 1.985 & 1.888 & $2.305(3)$ & - & 34.1 \\
\hline $7 \mathrm{~h}$ & 2.109 & 1.898 & $2.173(6)$ & - & 57.0 \\
\hline $7 \mathbf{i}$ & 2.111 & 1.898 & $2.175(5)$ & - & 55.3 \\
\hline $7 \mathbf{j}$ & 1.987 & 1.888 & $2.304(4)$ & - & 33.8 \\
\hline $7 \mathbf{k}$ & 1.969 & 1.881 & $2.326(3)$ & - & 35.9 \\
\hline 71 & 1.978 & 1.885 & $2.246(4)$ & - & 57.7 \\
\hline
\end{tabular}

${ }^{a}$ Average values calculated from two bond length values. ${ }^{b}$ Distortion parameter defined as sum of deviations from $90^{\circ}$ of the twelve cis angles in the coordination sphere. ${ }^{30}$
$\left.\left.\left(\mathrm{H}_{2} \mathrm{O}\right)\right\}_{2}\left\{\mu-\mathrm{Fe}(\mathrm{CN})_{5}(\mathrm{NO})\right\}\right]$ (5a) have been determined by single crystal X-ray diffraction. Magnetic measurements were performed on all of the prepared compounds including two additional compounds for which crystal structures were not determined: $\quad\left[\left\{\mathrm{Fe}(\mathrm{L} 4 \mathrm{a})\left(\mathrm{H}_{2} \mathrm{O}\right)\right\}_{2}\left\{\mu-\mathrm{Fe}(\mathrm{CN})_{5}(\mathrm{NO})\right\}\right] \cdot \mathrm{CH}_{3} \mathrm{OH} \quad$ (2a), $\left[\left\{\mathrm{Mn}(\mathrm{L} 4 \mathrm{a})\left(\mathrm{H}_{2} \mathrm{O}\right)\right\}_{2}\left\{\mu-\mathrm{Fe}(\mathrm{CN})_{5}(\mathrm{NO})\right\}\right] \cdot \mathrm{CH}_{3} \mathrm{OH}(\mathbf{2 b})$. Furthermore, we report a novel type of nitroprusside complex with an ionic structure, where the $\left.\left[\left\{\mathrm{Mn}(\mathrm{L} 4 \mathrm{e})\left(\mathrm{H}_{2} \mathrm{O}\right)\right\} \mu \mu-\mathrm{Fe}(\mathrm{CN})_{5}(\mathrm{NO})\right\}\right]^{-}$anion is charge balanced by the $\left[\left\{\mathrm{Mn}(\mathrm{L} 4 \mathrm{e})\left(\mathrm{H}_{2} \mathrm{O}\right)\left(\mathrm{CH}_{3} \mathrm{OH}\right)\right]^{+}\right.$cation $(6 \mathbf{6})$.

With the aim to elucidate the magnetic exchange and magnetic anisotropy in each herein reported compound, temperature and field dependent magnetic data were simultaneously fitted to provide trustworthy values of isotropic exchange constants $(J)$ and single-ion zero-field splitting parameters $(D)$. Furthermore, a thorough DFT study was undertaken to determine dominant super-exchange pathways and the roles of minor changes in the crystal structures on the overall magnetic exchanges. The ultimate goal of our investigations is to build up a magneto-structural correlation between the isotropic magnetic exchange constant $J$ and the structural parameters for the group of compounds containing $[\mathrm{M}(\mathrm{L} 4)(\mathrm{Solv})]^{+} \ldots[\mathrm{M}(\mathrm{L} 4)-(\mathrm{Solv})]^{+}$supramolecular dimers. So far several studies devoted to magnetic exchange mediated by $\mathrm{O}-\mathrm{H} \cdots \mathrm{O}$ hydrogen bonds have been published, ${ }^{29}$ but mainly on copper(II) complexes, in which only isotropic exchange is present. In our study, the situation is complicated by zero-field splitting of $\mathrm{Fe}(\mathrm{III})$ and $\mathrm{Mn}$ (III) atoms, and thus, advanced magnetic analysis had to be employed.

\section{Results and discussion}

\section{Crystal structures of trinuclear complexes $3 \mathrm{a}, 4 \mathrm{a}, 4 \mathrm{~b}$ and $5 \mathrm{a}$}

The selected bond lengths for herein and previously reported salen-type complexes are summarized in Table 1. The crystal data and structure refinements for compounds reported in this article are given in Table 2.

Table 2 Crystallographic data and structure refinement details for complexes 3a, 4a, 4b, 5a and 6b

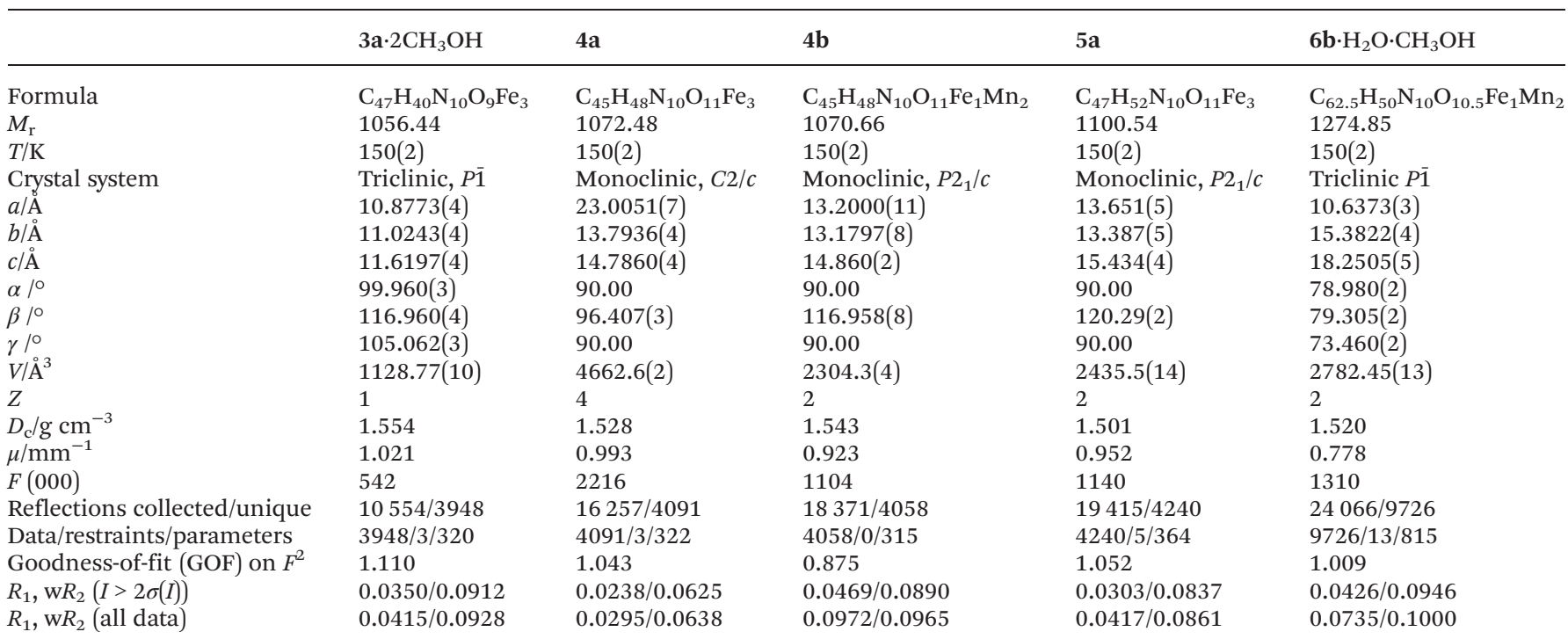


The molecular structures of these complexes are very similar, consisting of trinuclear $\left[\left\{\mathrm{M}^{\mathrm{III}}(\mathrm{L} 4)\left(\mathrm{H}_{2} \mathrm{O}\right)\right\}_{2}\{\mu-\mathrm{Fe}-\right.$ $\left.\left.(\mathrm{CN})_{5}(\mathrm{NO})\right\}\right]$ moieties $\left(\mathrm{M}^{\mathrm{III}}=\mathrm{Fe}^{\mathrm{III}}\right.$ or $\mathrm{Mn}^{\mathrm{III}}$, Fig. S1-S4 in $\left.\mathrm{ESI}^{\dagger}\right)$ which have slightly bent $\left\{\mathrm{H}_{2} \mathrm{O}-\mathrm{M}^{\mathrm{III}}-\mathrm{NC}-\mathrm{Fe}-\mathrm{CN}-\mathrm{M}^{\mathrm{III}}-\mathrm{H}_{2} \mathrm{O}\right\}$ arrangements (Fig. 1-3). The $\mathrm{M}^{\mathrm{III}} \cdots \mathrm{M}^{\mathrm{III}}$ separations within the trinuclear complexes are very similar (in $\AA$ ): 10.1621(6) in 3a, 10.1532(5) in $\mathbf{4 a}, 10.225(2)$ in $\mathbf{4 b}$ and 10.173(4) in 5a. The coordination polyhedra of the $\left[\mathrm{M}(\mathrm{L} 4)\left(\mathrm{H}_{2} \mathrm{O}\right)\right]^{+}$subunits can be described as axially elongated octahedrons, and the distortion is more obvious for the Mn(III) derivatives due to the JahnTeller effect. In general, based on herein and previously reported salen-type complexes, it can be concluded that the $\mathrm{Mn}$ (III) compounds show significantly longer axial (usually $\mathbf{M}$ $\mathrm{N}_{\mathrm{CN}}$ and $\mathrm{M}-\mathrm{O}_{\mathrm{S}}$ bonds; $\mathrm{N}_{\mathrm{CN}}$ stands for the nitrogen atom of the nitroprusside cyanido group, $\mathrm{O}_{\mathrm{S}}$ stands for the oxygen atom from the coordinated solvent molecule) bond lengths in comparison with the $\mathrm{Fe}(\mathrm{III})$ compounds $\left(\mathrm{ca} \cdot d\left(\mathrm{Mn}-\mathrm{N}_{\mathrm{CN}}\right)=2.30 \AA\right.$, $d\left(\mathrm{Fe}-\mathrm{N}_{\mathrm{CN}}\right)=2.17 \AA, d\left(\mathrm{Mn}-\mathrm{O}_{\mathrm{S}}\right)=2.27 \AA, d\left(\mathrm{Fe}-\mathrm{O}_{\mathrm{S}}\right)=2.10 \AA$, Table 1). On the contrary, the $\mathrm{M}-\mathrm{N}_{\mathrm{im}}$ bond lengths are longer in the case of the $\mathrm{Fe}(\mathrm{III})$ complexes $\left(\right.$ ca. $d\left(\mathrm{Mn}-\mathrm{N}_{\mathrm{im}}\right)=1.99 \AA$,
$d\left(\mathrm{Fe}-\mathrm{N}_{\mathrm{im}}\right)=2.11 \AA ; \mathrm{N}_{\mathrm{im}}$ stands for the nitrogen atom from the imino group of $\mathrm{L} 4$ ). The length of the $\mathrm{M}-\mathrm{O}_{\mathrm{Ph}}$ bonds is roughly the same for both central ions (Table $1 ; \mathrm{O}_{\mathrm{Ph}}$ stands for the phenolate oxygen atoms). The angular distortions from the ideal octahedron $\Sigma^{30}$ are obviously smaller for the Mn(III) compounds (Table 1 ).

As mentioned in the introduction, these trinuclear complexes belong to group (A), in which non-covalent connections between polynuclear species are provided by hydrogen bonding between coordinated Solv molecules and phenolate oxygen atoms and thus, roughly linear arrays of centrosymmetric and supramolecular $[\mathrm{Mn}(\mathrm{L} 4)(\mathrm{Solv})]^{+} \ldots[\mathrm{Mn}(\mathrm{L} 4)(\mathrm{Solv})]^{+}$ dimers connected by nitroprusside anions are formed. In the crystal structures of compounds $\mathbf{3 a}, \mathbf{4 a}, \mathbf{4} \mathbf{b}$ and $\mathbf{5 a}$, the Solv molecules (Solv $=\mathrm{H}_{2} \mathrm{O}$ ) form two basic types of interactions: (i) a simple $\mathrm{O}_{\mathrm{S}}-\mathrm{H} \cdots \mathrm{O}_{\mathrm{S}}$ hydrogen bond (in 3a) and (ii) a bifurcated hydrogen bond where two $\mathrm{H}$-atoms from the water molecule interact with four oxygen atom acceptors (two alkoxy $\left(\mathrm{O}_{\mathrm{A}}\right)$ and two phenolate oxygen atoms, in $\mathbf{4 a}, \mathbf{4 b}$ and $\mathbf{5 a}$ ). The bifurcated hydrogen bonding prolongs the donor...acceptor lengths; in

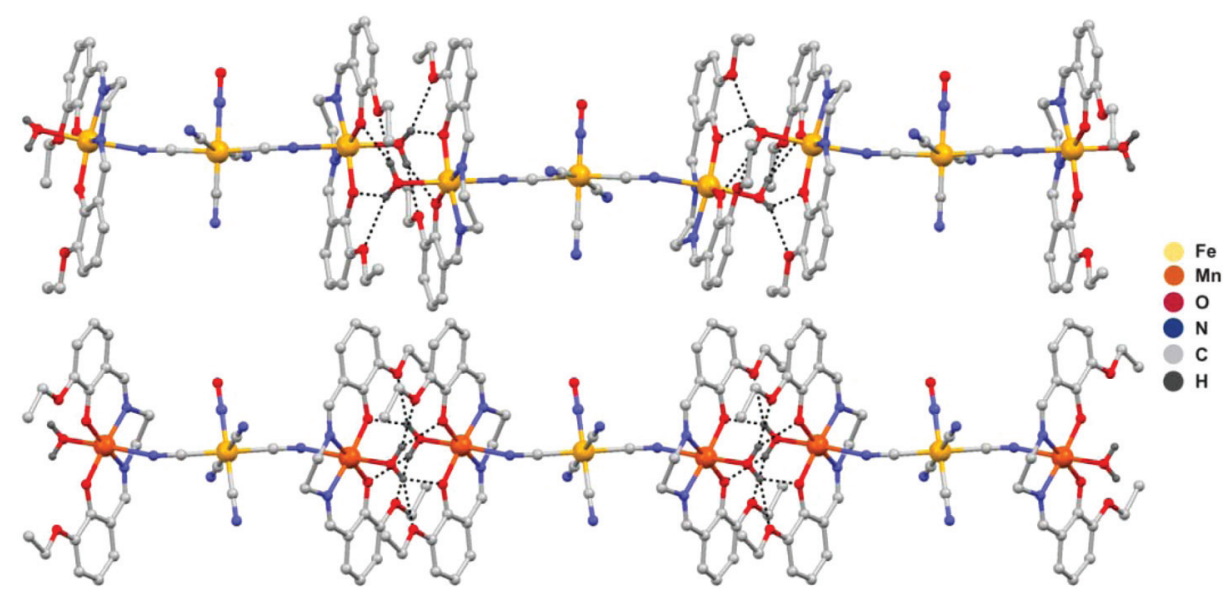

Fig. 1 Fragments of the crystal structures of complexes 4a (up) and $4 \mathrm{~b}$ (down). The hydrogen atoms are omitted for clarity, except for the atoms responsible for the formation of a "supramolecular dimer" in $4 \mathrm{a}$ and $4 \mathrm{~b}$ due to hydrogen bonds (dashed lines). Selected bond lengths and angles are shown in Fig. S2 and S3 in ESI. $\dagger$

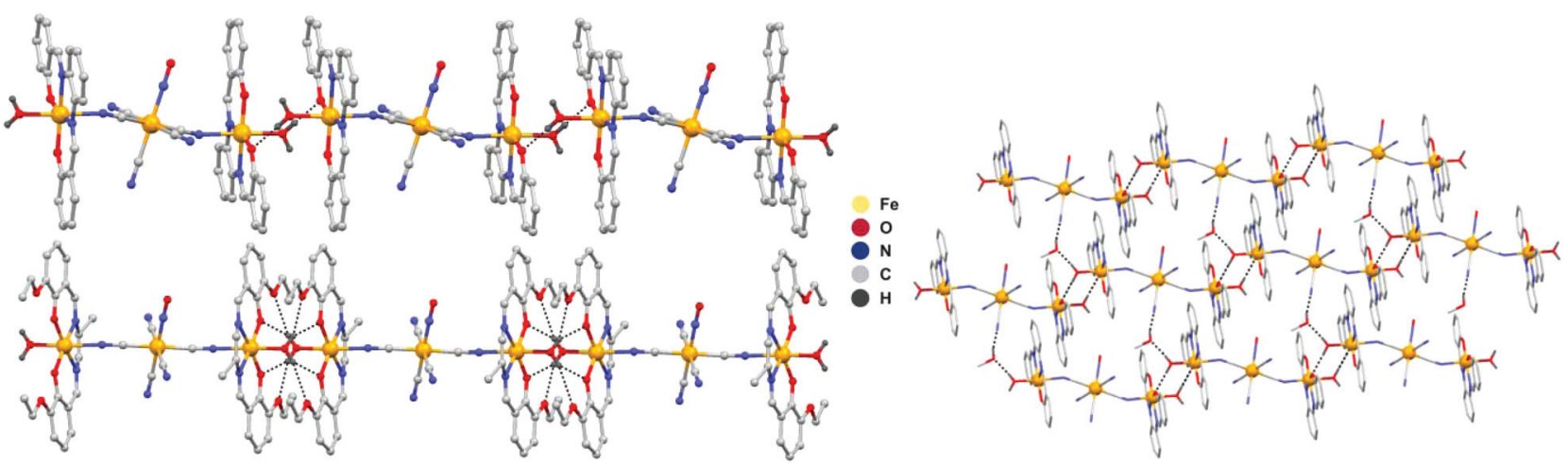

Fig. 2 Left: Fragments of the crystal structures of complexes 3a (up) and $5 a$ (down). The hydrogen atoms and methanol molecules (3a) are omitted for clarity, except for the atoms responsible for the formation of a "supramolecular dimer" in $3 a$ and $5 a$ due to hydrogen bonds (dashed lines). Selected bond lengths and angles are shown in Fig. S1 and S4 in ESI $\dagger$. Right: A view of the 2D supramolecular structure in 3a. 


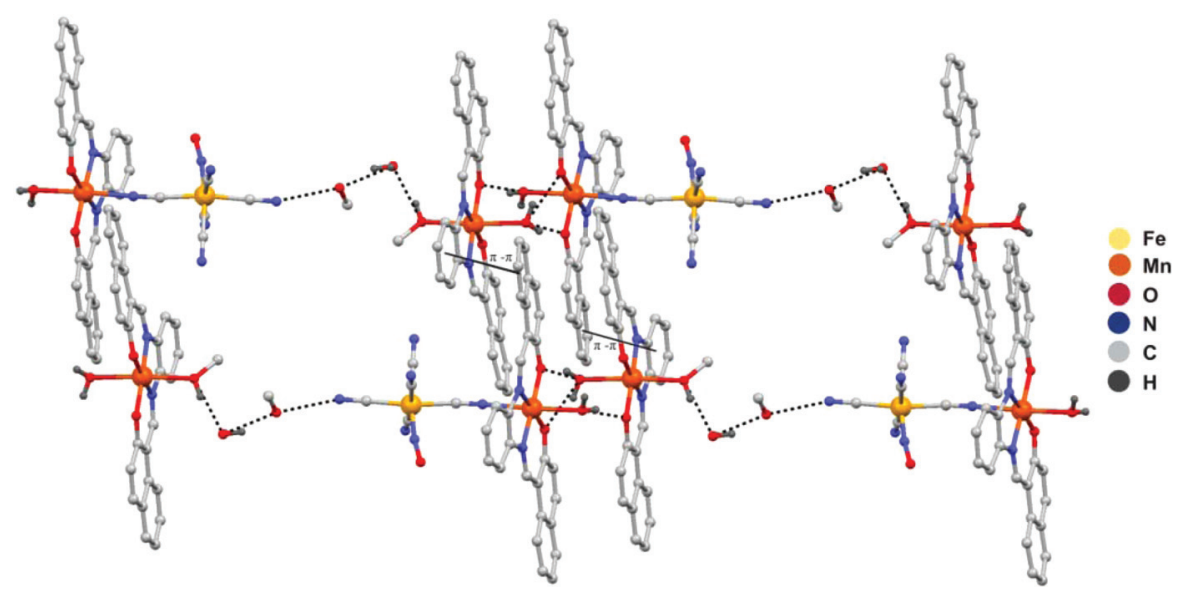

Fig. 3 Fragment of the crystal structure of complex $\mathbf{6 b}$. The hydrogen atoms are omitted for clarity, except for the atoms responsible for the formation of a "supramolecular dimer" in $6 \mathrm{~b}$ due to hydrogen bonds (dashed lines). Numerous $\pi-\pi$ stacking interactions within the complex are also highlighted. Selected bond lengths $(\AA \AA)$ and angles $\left(^{\circ}\right)$ are shown in Fig. S5 in ESI. $\dagger$

the case of $\mathrm{O}_{\mathrm{S}} \cdots \mathrm{O}_{\mathrm{Ph}}$ contacts (in $\left.\AA\right): d\left(\mathrm{O}_{\mathrm{S}} \cdots \mathrm{O}_{\mathrm{Ph}}\right)=2.690(3)$ in $3 \mathrm{a}$ vs. 2.792(2) and 2.927(2) in 4a, 2.851(3) and 2.934(3) in 4b, and 2.814(2) and 2.866(2) in 5a. The $\mathrm{O}_{\mathrm{S}} \cdots \mathrm{O}_{\mathrm{A}}$ hydrogen bonds are longer in general, however, in the crystal structure of $\mathbf{4 b}$ we observe one relatively short contact (in $\AA$ ): $d\left(\mathrm{O}_{\mathrm{S}} \cdots \mathrm{O}_{\mathrm{A}}\right)=3.024(2)$ and $3.248(2)$ in $\mathbf{4 a}, 2.866(3)$ and $3.115(4)$ in $\mathbf{4 b}$, and $3.064(2)$ and $3.279(2)$ in $\mathbf{5 a}$.

The $\mathrm{M}^{\mathrm{III}} \cdot \mathrm{M}^{\mathrm{III}}$ separations in the supramolecular dimers are within a relatively narrow range (in $\AA$ ): $4.8728(5)$ in $3 \mathrm{a}$, 4.5608(4) in 4a, 4.7132(9) in $\mathbf{4 b}$ and 4.594(2) in 5a. The crystal structure of $\mathbf{3 a}$ differs significantly from the structures of 4a, $\mathbf{4 b}$ and $5 \mathbf{a}$ due to the presence of a co-crystallized molecule of methanol. This extends the structural dimensionality of the compound to $2 \mathrm{D}$ by linking supramolecular chains $\left[\left\{\mathrm{Fe}(\mathrm{L} 4 \mathrm{~b})\left(\mathrm{H}_{2} \mathrm{O}\right)\right\}_{2}\left\{\mu-\mathrm{Fe}(\mathrm{CN})_{5}(\mathrm{NO})\right\}\right]_{n}$ together through hydrogen bonding between a coordinated water molecule and a methanol molecule which in turn is hydrogen bonded to a noncoordinated nitrogen atom from the nitroprusside bridge of a neighbouring complex (Fig. 2).

\section{Crystal structure of complex $6 b$}

The crystal structure of $\mathbf{6 b}$ is depicted in Fig. 3. It consists of the dimeric $\left[\left\{\mathrm{Mn}(\mathrm{L} 4 \mathrm{e})\left(\mathrm{H}_{2} \mathrm{O}\right)\right\}\left\{\mu-\mathrm{Fe}(\mathrm{CN})_{5} \mathrm{NO}\right\}\right]$ (6b mol1) and $\left[\left\{\mathrm{Mn}(\mathrm{L} 4 \mathrm{e})\left(\mathrm{H}_{2} \mathrm{O}\right)\left(\mathrm{CH}_{3} \mathrm{OH}\right)\right](\mathbf{6 b} \mathrm{mol} 2)\right.$ moieties, in which both manganese atoms are hexacoordinated with four donor atoms $\left(\mathrm{N}_{2} \mathrm{O}_{2}\right)$ coming from the $\mathrm{L} 4 \mathrm{e}^{2-}$ ligand. In $\mathbf{6 b}$ mol1 the remaining coordination sites (axial positions) are occupied by two oxygen atoms, coming from the coordinated water and methanol molecules. On the other hand, the axial positions in $\mathbf{6 b}$ mol2 are occupied by the oxygen atom from the water molecule and by the nitrogen atom from the bridging cyanido group of the nitroprusside. The average bond lengths are $(\mathrm{mol} 1, \mathrm{~mol} 2$; in $\AA): d\left(\mathrm{Mn}-\mathrm{N}_{\mathrm{im}}\right)=1.961,1.953 ; d\left(\mathrm{Mn}-\mathrm{O}_{\mathrm{Ph}}\right)=$ $1.882,1.868$. The axial bond lengths differ due to the different solvent molecules coordinated to the $\mathrm{Mn}(\mathrm{III})$ atoms (in $\AA$ ): $d$ $\left(\mathrm{Mn}-\mathrm{O}_{\mathrm{S}}\right)=2.292(3)\left(\mathrm{H}_{2} \mathrm{O}\right)$ in mol1 and 2.256(3) $\left(\mathrm{CH}_{3} \mathrm{OH}\right)$ and $2.309(3)\left(\mathrm{H}_{2} \mathrm{O}\right)$ in mol2. It must be noted that the crystal struc- ture of $\mathbf{6 b}$ exhibits substitutional disorder on mol2, where the methanol molecule (the main part, with occupation factor of 0.68 ) is partially substituted by a water molecule which is further hydrogen bonded to another disordered water molecule (Fig. S5 in ESI†).

Both complexes create 2D networks of hydrogen bonds owing to the co-crystallized water and methanol molecules (Fig. 3). The $\left[\left\{\mathrm{Mn}(\mathrm{L} 4 \mathrm{e})\left(\mathrm{H}_{2} \mathrm{O}\right)\right\}\left\{\mu-\mathrm{Fe}(\mathrm{CN})_{5} \mathrm{NO}\right\}\right]\left[\left\{\mathrm{Mn}(\mathrm{L} 4 \mathrm{e})\left(\mathrm{H}_{2} \mathrm{O}\right)\right.\right.$ $\left.\left(\mathrm{CH}_{3} \mathrm{OH}\right)\right]$ assembly (mol1 $\left.\cdots \mathrm{mol} 2\right)$, in which the interconnection between mol1 and mol2 is provided by hydrogen bonding between coordinated water molecules and complementary phenolate oxygen atoms, similarly to in compounds $\mathbf{3 a - 5 a}$, can be considered as the main building block of the crystal structure. The mol1 $\cdots \mathrm{mol} 2$ assembly is further propagated to a linear 1D chain by a series of hydrogen bonds; the coordinated methanol molecule from mol2 forms a hydrogen bond with a co-crystallized water molecule, which in turn hydrogen bonds to a co-crystallized methanol molecule which is in close contact with the adjacent cyanido group (the trans position with respect to the cyanido group coordinating the $\mathrm{Mn}$ atom) from the neighbouring mol1 $\cdots \operatorname{mol} 2$ assembly. Linear supramolecular chains are interconnected via hydrogen bonding between the coordinated water molecule from mol1 and the neighbouring cyanido group (the cis position with respect to the cyanido group coordinating the $\mathrm{Mn}$ atom), and between the co-crystallized water molecule and the cyanido group from the neighbouring mol1 moiety.

\section{Infrared spectroscopy}

The presence of the Schiff base in each of the complexes was indicated by FT-IR spectra measured in the range $400-4000 \mathrm{~cm}^{-1}$. The spectra of each of the compounds exhibit two weak intensity bands at 3115-3132 and 3025-3037 $\mathrm{cm}^{-1}$ corresponding to asymmetric and symmetric stretching vibrations of the aromatic $\mathrm{C}-\mathrm{H}$ groups. The characteristic bands assignable to the $\mathrm{C}=\mathrm{N}$ and $(\mathrm{C}-\mathrm{C})_{\text {ar }}$ vibrations were observed in the $1613-1625 \mathrm{~cm}^{-1}$ and $1437-1595 \mathrm{~cm}^{-1}$ regions, 
respectively, for all complexes. Formation of the cyanido-bridges in all the nitroprusside complexes are evidenced by the $\mathrm{C} \equiv \mathrm{N}$ stretching vibration bands in the $2000-2200 \mathrm{~cm}^{-1}$ region. The maximum at $2143 \mathrm{~cm}^{-1}$ in sodium nitroprusside dihydrate may be assigned to the vibration of the cyanido group, while the maxima associated with the same vibration in complexes $\mathbf{2 a - 6 \mathbf { b }}$ were observed in the range $2138-2163 \mathrm{~cm}^{-1} \cdot{ }^{31}$ The strong peaks in the region 1906-1922 $\mathrm{cm}^{-1}$ are assignable to the $\mathrm{N}=\mathrm{O}$ stretching vibrations, which are at lower wavenumbers than that found for the same vibration in the complex $\mathrm{Na}_{2}\left[\mathrm{Fe}(\mathrm{CN})_{5} \mathrm{NO}\right] \cdot 2 \mathrm{H}_{2} \mathrm{O}\left(1936 \mathrm{~cm}^{-1}\right)$.

\section{Magnetic properties}

In all the presented compounds, we can observe the formation of quasi-dimers amongst $\left[\left\{\mathrm{Mn}^{\mathrm{III}}(\mathrm{L} 4)\left(\mathrm{H}_{2} \mathrm{O}\right)\right\}\right]^{+}$or $\left[\left\{\mathrm{Fe}^{\mathrm{III}}(\mathrm{L} 4)\right.\right.$ $\left.\left.\left(\mathrm{H}_{2} \mathrm{O}\right)\right\}\right]^{+}$subunits, held together by hydrogen bonds between coordinated solvent molecules and phenolic oxygen atoms. Within these quasi-dimers, the $\mathrm{Mn} \cdots \mathrm{Mn}$ and Fe...Fe separations vary between 4.71-5.06 $\AA$, and 4.59-4.87 $\AA$, respectively, in contrast to their large interatomic separations (more than $10 \AA$ ) through covalent bonds formed by diamagnetic nitroprusside bridges.

These structural aspects strongly suggest that the superexchange mechanism is mainly active through hydrogen bonds. The nature of the magnetic exchange can be estimated by inspecting the temperature dependence of susceptibility and the effective magnetic moment of these compounds. The presence of the maximum of the susceptibility $(T<10 \mathrm{~K})$ is a fingerprint of the antiferromagnetically coupled homospin dimer. This results in a decrease in $\mu_{\text {eff }} / \mu_{\mathrm{B}}$ on cooling. Moreover, the interplay of the zero-field splitting on the magnetic properties cannot be neglected, especially for Mn(III) atoms.

Therefore the following spin Hamiltonian was postulated

$$
\hat{H}=-J\left(\vec{S}_{1} \cdot \vec{S}_{2}\right)+\sum_{i=1}^{2} D_{i}\left(\hat{S}_{i, z}{ }^{2}-\hat{S}_{i}{ }^{2} / 3\right)+\mu_{\mathrm{B}} B g_{i} \hat{S}_{i, a}-z j\left\langle\hat{S}_{a}\right\rangle \hat{S}_{a}
$$

where the first term stands for the isotropic exchange $(J)$, the second part is due to the zero-field splitting ( $D-$ an axial single-ion ZFS parameter), the third part is the Zeeman term and the last expression represented with the $z j$ variable is the common molecular-field correction parameter, which is due to small intra/inter-chain molecular interactions. The $\left\langle S_{a}\right\rangle$ is a thermal average of the molecular spin projection in the $a$ direction of the magnetic field defined as $\mathbf{B}_{a}=B(\sin \theta \cos \varphi$, $\sin \theta \sin \varphi, \cos \theta)$ with the help of polar coordinates. Then, the molar magnetization in the $a$ direction of the magnetic field can be numerically calculated as

$$
M_{a}=-N_{\mathrm{A}} \frac{\sum_{i}\left(\sum_{k} \sum_{l} C_{i k}^{+}\left(Z_{a}\right)_{k l} C_{l i}\right) \exp \left(-\varepsilon_{a, i} / k T\right)}{\sum_{i} \exp \left(-\varepsilon_{a, i} / k T\right)}
$$

where $Z_{a}$ is the matrix element of the Zeeman term for the $a$ direction of the magnetic field and $C$ are the eigenvectors resulting from the diagonalization of the complete spin Hamiltonian matrix. Then, the averaged molar magnetization of the powder sample was calculated as integral (orientational) average

$$
M_{\mathrm{mol}}=1 / 4 \pi \int_{0}^{2 \pi} \int_{0}^{\pi} M_{a} \sin \theta \mathrm{d} \theta \mathrm{d} \varphi
$$

With the aim to bring more insight into the general properties of the antiferromagnetically coupled dimer with ZFS, the shift in temperature of the maximum of the susceptibility $\left(T_{\max }\right)$ was inspected for varying ratios of $D / J$, for either $S_{1}=S_{2}=2$ or $S_{1}=S_{2}=5 / 2$ (Fig. 4). There is a simple formula which interconnects the strength of the antiferromagnetic exchange with $T_{\max }$, but it is available only for the isotropic case: $|J| / k T_{\max }=0.462$ for $S_{1}=S_{2}=2$ and $|J| / k T_{\max }=0.347$ for $S_{1}=S_{2}=5 / 2$. In both cases, introducing the non-zero zero-field splitting results in an increase in $T_{\max }$, and this change is more emphasized for $D<0$ (Fig. 4).

As both antiferromagnetic exchange and ZFS have similar effects on magnetic properties, the decrease in $\mu_{\text {eff }} / \mu_{\mathrm{B}}$, both the temperature and field dependent magnetization data were experimentally acquired and concurrently used in finding the best-fit parameters of the above introduced spin Hamiltonian (eqn (1)). Furthermore, the standard deviations of the varied parameters were calculated with $95 \%$ probability confidence limits. $^{32}$
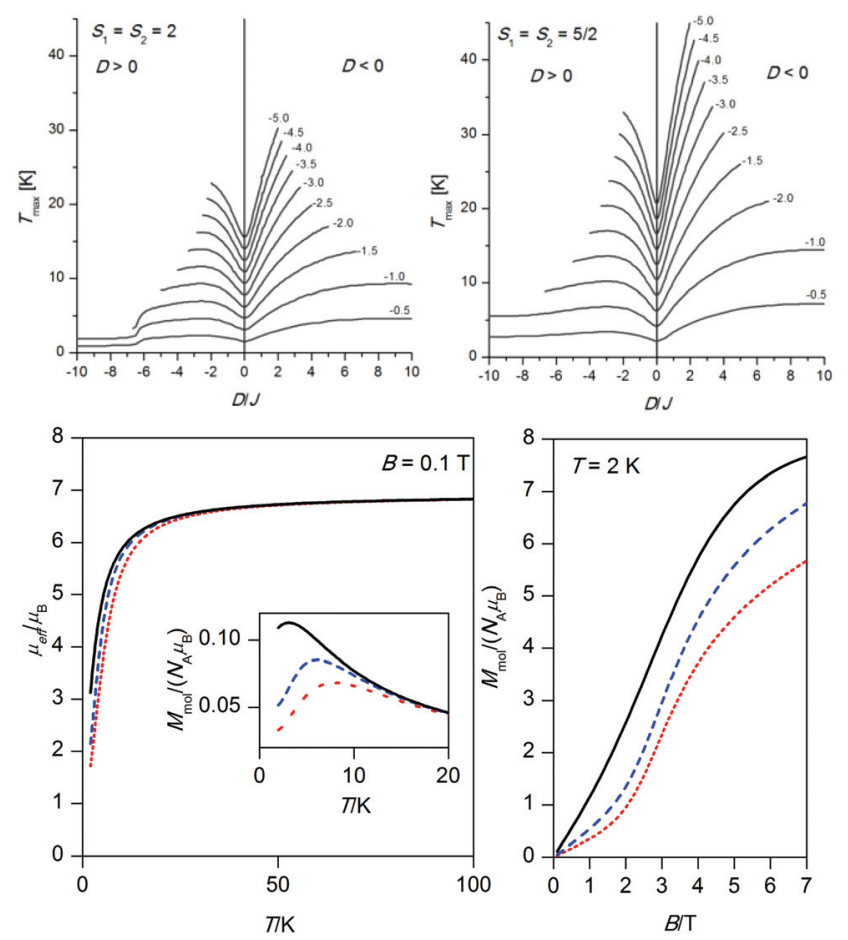

Fig. 4 Top: Modelling of the interplay of the antiferromagnetic exchange $(J)$ and the single-ion zero-field splitting $(D)$ on the temperature of the maximum of the molar magnetization (or the mean susceptibility), $T_{\max }$ for dinuclear systems. The lines' labels correspond to $\mathrm{J}$ values. The $D$-parameter was varied from -10 to $+10 \mathrm{~cm}^{-1}$. Bottom: variation of the magnetic properties for the $S_{1}=S_{2}=2$ dimer, with the fixed parameters $\mathrm{J}=-1 \mathrm{~cm}^{-1}$ and $g=2.0$, while $D$ was varied: $D=0$ (black full line), $D=-2 \mathrm{~cm}^{-1}$ (blue dashed line) and $D=-4 \mathrm{~cm}^{-1}$ (red dotted line). 


\section{Dinuclear complex 6b}

The unique molecular and crystal structure of $\mathbf{6 b}$ results in the formation of quasi linear and discrete trimers of type $\mathrm{Mn}^{\mathrm{III}} \ldots$ $\mathrm{Mn}^{\mathrm{III}} \ldots \mathrm{Fe}^{\mathrm{II}}$ in which paramagnetic manganese atoms are connected through hydrogen bonds $(d(\mathrm{Mn} \cdots \mathrm{Mn})=5.0575(7) \AA)$ and the diamagnetic nitroprusside anion serves as a terminal entity. This gives us an opportunity to study the magnetic exchange of the $\mathrm{Mn}^{\mathrm{III}}-\mathrm{Mn}^{\mathrm{III}}$ type mediated by water-hydrogen bonds, unaffected by bridging through nitroprusside as found in the remaining reported complexes. The experimental magnetic data are presented in Fig. 5. The room temperature effective magnetic moment of $\mathbf{6 b}$ is $7.1 \mu_{\mathrm{B}}$, which is very close to the theoretical value of $6.93 \mu_{\mathrm{B}}$ for two paramagnetic noninteracting centres with $S=2(g=2.0)$. The susceptibility is increasing on cooling and is reaching its maximum at $6.5 \mathrm{~K}$, which is also accompanied by a decrease in $\mu_{\text {eff }}$ below $50 \mathrm{~K}$ down to $2.1 \mu_{\mathrm{B}}$ at $1.9 \mathrm{~K}$. The isothermal magnetization at $2 \mathrm{~K}$ is not saturated even at $B=7 \mathrm{~T}$ and has a value of $M_{\mathrm{mol}} / N_{\mathrm{A}} \mu_{\mathrm{B}}=$ 6.2, which is below the saturation limit of $M_{\mathrm{mol}} / N_{\mathrm{A}} \mu_{\mathrm{B}}=8(2 \times S$ $=2$ and $g=2.0$ ). By applying eqn (1)-(3) to both temperature and field dependent magnetic data, we obtained $J=-0.72(1)$ $\mathrm{cm}^{-1}, g=2.048(1), D=-3.65(9) \mathrm{cm}^{-1}$ and $z j=-0.06(1) \mathrm{cm}^{-1}$ (Fig. 5). The negative and large value of the $D$-parameter is in agreement with the elongated octahedrons of the $\mathrm{Mn}$ (III) centres due to the Jahn-Teller effect. However, the coordination chromophores of the respective $\mathrm{Mn}$ (III) centres differ in one apical position $-\left\{\mathrm{MnO}_{3} \mathrm{~N}_{3}\right\}$ for $\mathrm{Mn} 1$ and $\left\{\mathrm{MnO}_{4} \mathrm{~N}_{2}\right\}$ for Mn2 (Fig. 3), and therefore the calculated $D$-value serves as an average value of both distinct $\mathrm{Mn}$ (III) centers. The most important outcome is that considerably large magnetic exchange is mediated by hydrogen bonds between Mn(III) centers.

\section{Trinuclear $\left[\left\{\mathrm{Mn}(\mathrm{L} 4)\left(\mathrm{H}_{2} \mathrm{O}\right)\right\}_{2}\left\{\mu-\mathrm{Fe}(\mathrm{CN})_{5}(\mathrm{NO})\right\}\right] \cdot \mathrm{CCH}_{3} \mathrm{OH}$ complexes $4 \mathrm{~b}$ and $2 \mathrm{~b}$}

Compound $\mathbf{4 b}$ shows very similar magnetic properties to compound $\mathbf{6 b}$ (Fig. 5), which justifies the presumption that dominant magnetic exchange is mediated through hydrogen bonds $(d(\mathrm{Mn} \cdots \mathrm{Mn})=4.7132(9) \AA)$ and not through the diamagnetic nitroprusside anion $(d(\mathrm{Mn} \cdots \mathrm{Mn})=10.225(2) \AA)$. Thus, the magnetic data of $\mathbf{4 b}$ were treated using the same procedure as for $\mathbf{6 b}$ under the condition that $D_{1}=D_{2}$, because there is only one $\mathrm{Mn}$ atom in the asymmetric unit. The resulting parameters are $J=-0.79(1) \mathrm{cm}^{-1}, g=1.981(2), D=-3.7(1) \mathrm{cm}^{-1}$ and $z j=+0.12(2) \mathrm{cm}^{-1}$ (Fig. 5). The last reported Mn(III) compound is complex $\mathbf{2 b}$, which exhibits comparable properties to compounds $\mathbf{4 b}$ and $\mathbf{6 b}$ (Fig. 5). Thus, we used the same model despite the absence of its X-ray crystal structure. The best fit was obtained with the following parameters: $J=-0.55(1) \mathrm{cm}^{-1}$, $g=1.987(2), D=-3.5(2) \mathrm{cm}^{-1}$ and $z j=-0.10(2) \mathrm{cm}^{-1}$ (Fig. 5).

\section{Trinuclear $\left[\left\{\mathrm{Fe}(\mathrm{L4})\left(\mathrm{H}_{2} \mathrm{O}\right)\right\}_{2}\left\{\mu-\mathrm{Fe}(\mathrm{CN})_{5}(\mathrm{NO})\right\}\right] \cdot x \mathrm{CH}_{3} \mathrm{OH}$ complexes $2 \mathrm{a}, 3 \mathrm{a}, 4 \mathrm{a}$ and $5 \mathrm{a}$}

The magnetic behaviours of the trinuclear Fe(III)-nitroprusside complexes $\mathbf{2 a}, \mathbf{3 a}, \mathbf{4 a}$ and $\mathbf{5 a}$ were found to be very similar to one another (Fig. 6). The room temperature values of the
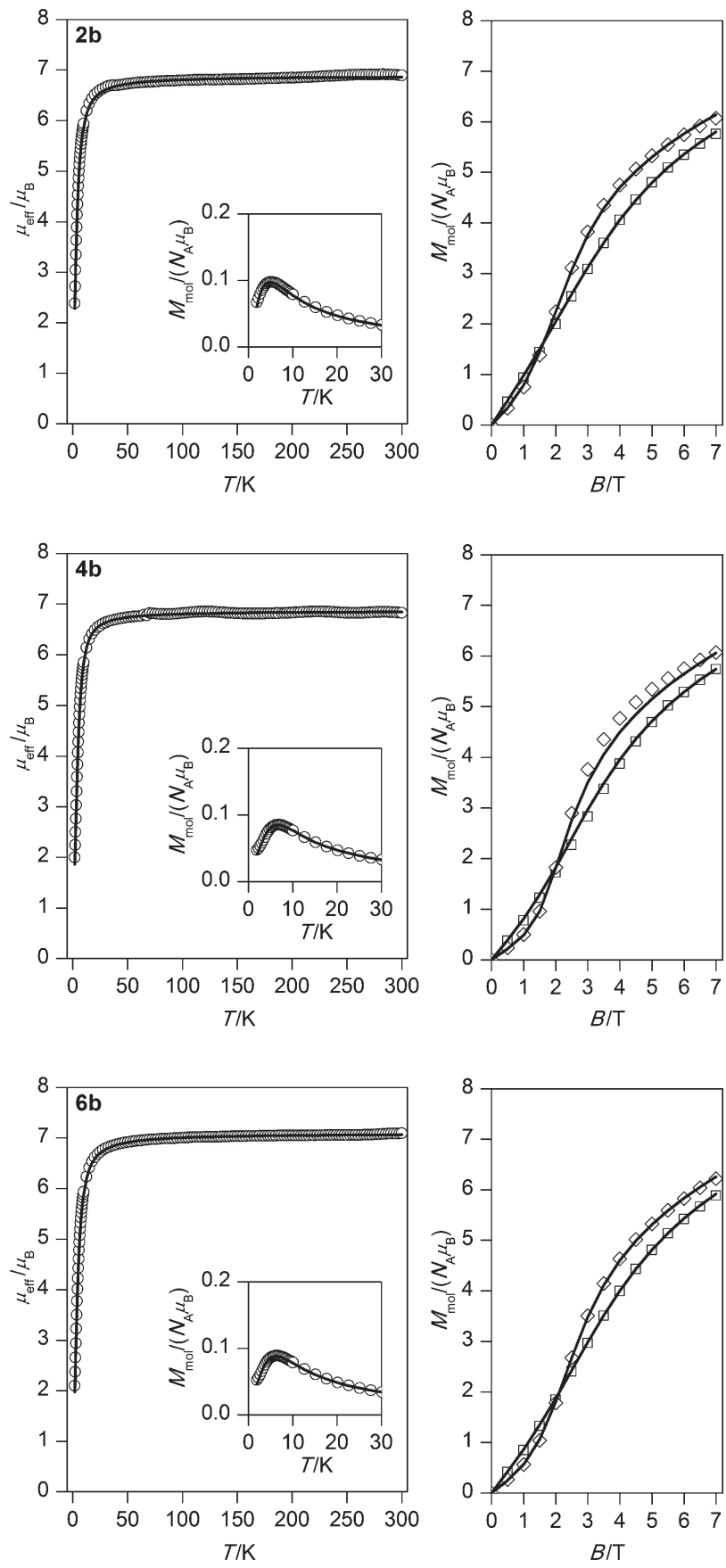

Fig. 5 Magnetic properties of 2b, $4 b$ and $6 \mathrm{~b}$. Each plot shows the temperature dependence of the effective magnetic moment (calculated from the temperature dependence of magnetization at $B=0.1 \mathrm{~T}$; inset) and the isothermal magnetizations measured at $T=2.0(\diamond)$ and $4.6 \mathrm{~K}(\square)$. Empty symbols - experimental data, full lines - the best fit calculated with $J=-0.55(1) \mathrm{cm}^{-1}, g=1.987(2), D=-3.5(2) \mathrm{cm}^{-1}$ and $z j=-0.10(2)$ $\mathrm{cm}^{-1}$ for $2 \mathrm{~b}, \mathrm{~J}=-0.79(1) \mathrm{cm}^{-1}, g=1.981(2), D=-3.7(1) \mathrm{cm}^{-1}$ and $z j=$ $+0.12(2) \mathrm{cm}^{-1}$ for $4 \mathrm{~b}$ and $J=-0.72(1) \mathrm{cm}^{-1}, g=2.048(1), D=-3.65(9)$ $\mathrm{cm}^{-1}$ and $z j=-0.06(1) \mathrm{cm}^{-1}$ for $6 \mathrm{~b}$.

effective magnetic moment are in the range $8.42-8.57 \mu_{\mathrm{B}}$, which is very close to the theoretical value of $8.37 \mu_{\mathrm{B}}$ for two paramagnetic non-interacting centres with $S=5 / 2(g=2.0)$. Upon cooling, the $\mu_{\mathrm{eff}} / \mu_{\mathrm{B}}$ dependencies are almost constant 

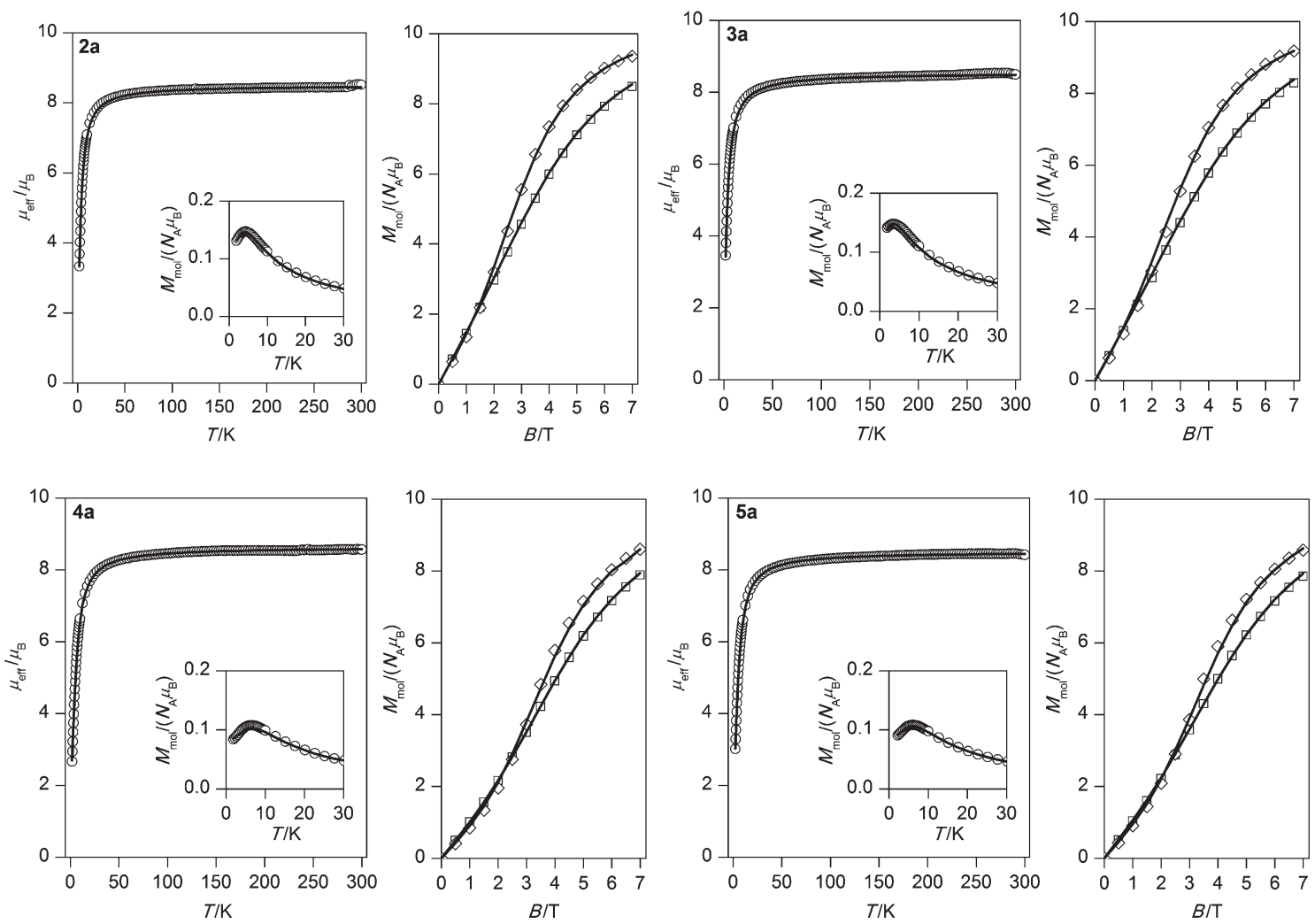

Fig. 6 Magnetic properties of 2a, 3a, 4a and 5a. Each plot shows the temperature dependence of the effective magnetic moment (calculated from the temperature dependence of magnetization at $B=0.1 \mathrm{~T}$; inset) and the isothermal magnetizations measured at $T=2.0(\diamond)$ and $4.6 \mathrm{~K}(\square)$. Empty symbols - experimental data, full lines - the best fit calculated with: $J=-0.64(2) \mathrm{cm}^{-1}, g=2.031(2), D=+1.1(2) \mathrm{cm}^{-1} \mathrm{and}_{z j}=-0.09(2) \mathrm{cm}^{-1}$ for $2 \mathrm{a}$, $J=-0.53(2) \mathrm{cm}^{-1}, g=2.042(3), D=+1.3(2) \mathrm{cm}^{-1}$ and $z j=-0.24(3) \mathrm{cm}^{-1}$ for $3 a, J=-1.01(4) \mathrm{cm}^{-1}, g=2.064(3), D=+1.9(3) \mathrm{cm}^{-1}$ and $z j=+0.03(3)$ $\mathrm{cm}^{-1}$ for $4 \mathrm{a}$ and $J=-0.94(2) \mathrm{cm}^{-1}, g=2.033(1), D=+1.6(2) \mathrm{cm}^{-1}$ and $z j=-0.026(4) \mathrm{cm}^{-1}$ for $5 a$.

down to $50 \mathrm{~K}$ and then they start to decrease to values of 3.33 , 3.46, 2.68 and 2.73 at $T=1.9 \mathrm{~K}$ for $\mathbf{2 a}, 3 \mathbf{a}, \mathbf{4 a}$, and $\mathbf{5 a}$, respectively.

Furthermore, the maxima of the molar magnetization (or mean molar susceptibility) ranged from 3.5 to $6.5 \mathrm{~K}$. This fact indicates the presence of antiferromagnetic exchange between $\mathrm{Fe}(\mathrm{III})$ centres, mediated by hydrogen bonds and/or the zerofield splitting of the $\mathrm{Fe}(\mathrm{III})$ centers. Moreover, the isothermal magnetization measurements at liquid helium temperatures (2.0 and $4.6 \mathrm{~K})$ support this presumption, because the experimental values of $M_{\mathrm{mol}} / N_{\mathrm{A}} \mu_{\mathrm{B}}$ are below the theoretical saturation value $M_{\mathrm{mol}} / N_{\mathrm{A}} \mu_{\mathrm{B}}=g \cdot S \cdot 2=10(g=2.0, S=5 / 2)$ (Fig. 6). Therefore, the same spin Hamiltonian was used as in eqn (1), but in this case $S_{1}=S_{2}=5 / 2$ holds. It must be stressed that including the ZFS term has been essential to reliably fit all experimental data together. We have found that slightly better fits could be obtained for positive rather than negative $D$-parameter values and both sets of values are tabulated for each of the presented compounds in Table 3 (see also Fig. 6 and Fig. S9-12, ESI $\dagger$ ). Evidently, weak antiferromagnetic exchange was found in the range -0.52 to $-1.05 \mathrm{~cm}^{-1}$. In the case of positive $D$-parameters, the $|D / J|$ ratios vary between 1.70 and 2.45 , but in the case of negative $D$-parameters, the $|D / J|$ ratios vary between 0.50 and 1.15 . To summarize, the values of the antiferromagnetic exchange in $\mathrm{Mn}(\mathrm{III})$ and $\mathrm{Fe}(\mathrm{III})$ compounds 2a-6b were found to vary in a narrow range between $-0.52 \mathrm{~cm}^{-1}$ and $-1.05 \mathrm{~cm}^{-1}$, but the ZFS is much larger for the $\mathrm{Mn}$ (III) complexes. This is an expected feature for Mn(III) atoms due to the Jahn-Teller effect and larger distortion of the coordination polyhedra. ${ }^{33}$

Furthermore, we strived to find clear magneto-structural correlations either for isotropic exchange $(J)$ or magnetic anisotropy $(D)$ in the reported series of compounds by taking into account various structural parameters. However, the $D$-parameter does not simply correlate with geometric deformation of the coordination chromophore $(\Sigma)$, which can be explained by the complexity and variedness of the donor atoms. Conversely, there are some remarks concerning the isotropic exchange which must be taken into account: our previous results ${ }^{20}$ predicted weaker exchange interactions within the supramolecular dimer $[\mathrm{M}(\mathrm{L} 4)(\mathrm{Solv})]^{+} \ldots[\mathrm{M}(\mathrm{L} 4)(\mathrm{Solv})]^{+}$when Solv $=\mathrm{CH}_{3} \mathrm{OH}$ and stronger ones when Solv $=\mathrm{H}_{2} \mathrm{O}$. As can be seen from Table 3, this prediction holds true; the compounds containing $\left[\mathrm{M}(\mathrm{L} 4)\left(\mathrm{CH}_{3} \mathrm{OH}\right)\right]^{+}$fragments possess weaker exchange interactions with $J$ values ranging from -0.3 to $-0.6 \mathrm{~cm}^{-1}$, while the compounds containing $\left[\mathrm{M}(\mathrm{L} 4)\left(\mathrm{H}_{2} \mathrm{O}\right)\right]^{+}$ fragments have lower $J$ values ranging from -0.7 to $-1.3 \mathrm{~cm}^{-1}$ (when not including most probably overestimated $J$ values, due 
Table 3 Summary of structural details, results from magnetic analysis and DFT calculations for iron(III) and manganese(III) nitroprusside/polythiocyanidoplatinate-bridged complexes

\begin{tabular}{|c|c|c|c|c|c|c|c|c|c|c|}
\hline Compound & \multicolumn{4}{|c|}{ Selected structural data ${ }^{a}$} & \multicolumn{4}{|c|}{ Magnetic analysis data ${ }^{b}$} & \multicolumn{2}{|c|}{ DFT calculated data } \\
\hline $2 a$ & - & - & - & - & $\begin{array}{l}-0.64(2) \\
-0.67(5)\end{array}$ & $\begin{array}{l}2.031(2) \\
2.033(3)\end{array}$ & $\begin{array}{l}+1.1(2) \\
-0.48(7)\end{array}$ & $\begin{array}{l}-0.09(2) \\
-0.13(5)\end{array}$ & & \\
\hline $3 a$ & $4.8728(5)$ & $10.1621(6)$ & $3.682(2)$ & $\begin{array}{l}3.459(2) \\
2.690(3)\end{array}$ & $\begin{array}{l}-0.53(2) \\
-0.52(6)\end{array}$ & $\begin{array}{l}2.042(3) \\
2.044(3)\end{array}$ & $\begin{array}{l}+1.3(2) \\
-0.6(1)\end{array}$ & $\begin{array}{l}-0.24(3) \\
-0.29(5)\end{array}$ & $\begin{array}{l}30.02 / 5.02 \\
30.02 / 5.02\end{array}$ & $-0.45 /-0.54$ \\
\hline $5 \mathbf{a}$ & $4.593(2)$ & $10.173(4)$ & $3.338(2)$ & $\begin{array}{l}2.865(2) \\
2.814(2)\end{array}$ & $\begin{array}{l}-0.94(2) \\
-1.05(4)\end{array}$ & $\begin{array}{l}2.033(1) \\
2.036(2)\end{array}$ & $\begin{array}{l}+1.6(2) \\
-0.53(5)\end{array}$ & $\begin{array}{l}-0.026(4) \\
-0.02(4)\end{array}$ & $\begin{array}{l}30.02 / 5.02 \\
30.02 / 5.02\end{array}$ & $\begin{array}{l}-0.50 /-0.60 \\
-0.86 /-1.04^{f}\end{array}$ \\
\hline $2 \mathbf{b}$ & & & & & $-0.55(1)$ & $1.987(2)$ & $-3.5(2)$ & $-0.10(2)$ & & \\
\hline $4 b$ & $4.7132(9)$ & $10.225(2)$ & $3.296(3)$ & $\begin{array}{l}2.934(3) \\
2.851(3)\end{array}$ & $-0.79(1)$ & $1.981(2)$ & $-3.7(1)$ & $+0.12(2)$ & $\begin{array}{l}20.07 / 4.07 \\
20.07 / 4.07\end{array}$ & $\begin{array}{l}-0.59 /-0.74 \\
-0.94 /-1.16^{f}\end{array}$ \\
\hline $6 b$ & $5.0575(7)$ & - & $\begin{array}{l}3.534(3) \\
3.579(3)\end{array}$ & $\begin{array}{l}3.243(3) \\
3.022(3)\end{array}$ & $-0.72(1)$ & $2.048(1)$ & $-3.65(9)$ & $-0.06(1)$ & $20.07 / 4.07$ & $-0.55 /-0.68$ \\
\hline $7 d$ & $5.067(2)$ & $10.400(2)$ & $\begin{array}{l}3.496(6) \\
3.748(6)\end{array}$ & $\begin{array}{l}3.089(6) \\
2.910(6)\end{array}$ & $-1.90^{e}$ & 2.0 & - & - & $20.08 / 4.08$ & $-0.61 /-0.76$ \\
\hline $7 e$ & $4.694(1)$ & $10.388(3)$ & $3.303(2)$ & $\begin{array}{l}2.913(2) \\
2.858(2)\end{array}$ & - & - & - & - & $\begin{array}{l}20.07 / 4.07 \\
20.07 / 4.07\end{array}$ & $\begin{array}{l}-0.50 /-0.62 \\
-0.82 /-1.04^{f}\end{array}$ \\
\hline 8 & $4.7007(9)$ & $12.5840(8)$ & $3.242(4)$ & $\begin{array}{l}2.882(4) \\
2.930(5)\end{array}$ & -0.88 & 2.09 & -3.06 & +0.21 & $\begin{array}{l}20.09 / 4.09 \\
20.08 / 4.08\end{array}$ & $\begin{array}{l}-0.45 /-0.56 \\
-0.82 /-1.02^{f}\end{array}$ \\
\hline 9 & $4.858(2)$ & $12.017(2)$ & $\begin{array}{l}3.365(8) \\
3.550(8)\end{array}$ & $\begin{array}{l}2.707(8), 2.806(8) \\
2.779(8), 2.834(8)\end{array}$ & $-1.31(6)$ & $1.848(2)$ & $-2.2(1)$ & $-0.41(5)$ & $\begin{array}{l}20.07 / 4.07 \\
20.07 / 4.07\end{array}$ & $\begin{array}{l}-0.76 /-0.94 \\
-1.40 /-1.74^{f}\end{array}$ \\
\hline $\begin{array}{l}10 \\
11\end{array}$ & $\begin{array}{l}5.004(2) \\
5.0682(2)\end{array}$ & $\begin{array}{l}12.044(2) \\
11.749(3)\end{array}$ & $\begin{array}{l}3.469(3) \\
3.764(2)\end{array}$ & $\begin{array}{l}2.728(3) \\
2.777(2)\end{array}$ & $\begin{array}{l}-0.53(1) \\
-0.47(1)\end{array}$ & $\begin{array}{l}1.879(2) \\
1.889(2)\end{array}$ & $\begin{array}{l}-4.6(2) \\
-3.6(1)\end{array}$ & $\begin{array}{l}+0.23(2) \\
+0.03(1)\end{array}$ & $\begin{array}{l}20.08 / 4.08 \\
20.08 / 4.08\end{array}$ & $\begin{array}{l}-0.54 /-0.68 \\
-0.33 /-0.42\end{array}$ \\
\hline
\end{tabular}

${ }^{a} \mathbf{M} \cdots \mathbf{M}^{*}$ is the shortest distance between metal atoms bridged through water mediated hydrogen bonds; $\mathbf{M} \cdots \mathbf{M}$ is the shortest distance between metal atoms bridged by nitroprusside or polythiocyanidoplatinate; $\mathrm{O}_{\mathrm{Ph}} \cdots \mathrm{O}_{\mathrm{Ph}^{*}}{ }^{*}$ and $\mathrm{O}_{\mathrm{Ph}} \cdots \mathrm{O}_{\mathrm{S}}{ }^{*}$ are distances between the oxygen atoms of two phenol groups, or the oxygen atom of a phenol group and the oxygen atom of a water/methanol molecule, attached to different metal atoms $\mathrm{M}$ and $\mathrm{M}^{*} .{ }^{b} J$-values reported in the literature were scaled according to the spin Hamiltonian in eqn (1). ${ }^{c}$ Ref. $22 .{ }^{d}$ Ref. $23 .{ }^{e}$ Ref. 24 , comment: $J$-value is most probably overestimated due to omitting the ZFS term. ${ }^{f}$ Results based on DFT calculations performed on molecular fragments, in which hydrogen atoms were optimized with BP86/def2-TZVP(-f).

to the ZFS term being omitted in the magnetic data analysis, for details see Table 3). From the collected data it seems to be apparent that the difference in the quality of the exchange interactions mediated between coordinated methanol and water molecules is not caused by the intrinsic difference between these two solvents, but is most probably due to the different number of hydrogen bonds formed by each particular solvent molecule: $\mathrm{CH}_{3} \mathrm{OH}$ ( 2 hydrogen bonds within the dimer), $\mathrm{H}_{2} \mathrm{O}$ (usually 4 hydrogen bonds). This can be supported by two examples from the present series of nitroprusside bridged compounds.

Compound 3a represents a novel structural type of the $\left[\mathrm{M}(\mathrm{L} 4)\left(\mathrm{H}_{2} \mathrm{O}\right)\right]^{+} \ldots\left[\mathrm{M}(\mathrm{L} 4)\left(\mathrm{H}_{2} \mathrm{O}\right)\right]^{+}$supramolecular dimer; it is held by two hydrogen bonds whereas two other remaining hydrogen atoms point to solvent molecules within the lattice (Fig. 2 and 7). Noticeably, the value of the coupling constant $(J=$ $\left.-0.52 \mathrm{~cm}^{-1}\right)$ is very similar to those observed for the compounds with Solv $=\mathrm{CH}_{3} \mathrm{OH}$ (Table 3). Furthermore, compound $\mathbf{6 b}$ has another unique asymmetric dimeric synthon with three supportive hydrogen bonds (Fig. 3 and 7); the strength of the exchange interaction $\left(J=-0.72 \mathrm{~cm}^{-1}\right)$ is in between the values typical for $\mathrm{CH}_{3} \mathrm{OH}$ and $\mathrm{H}_{2} \mathrm{O}$.
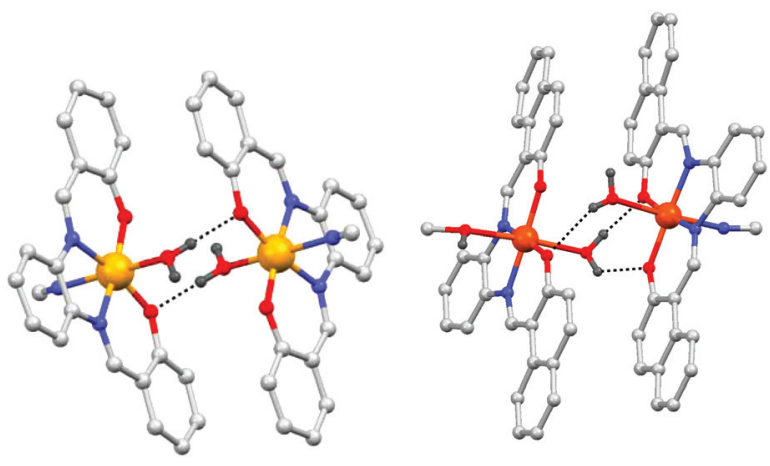

Fig. 7 A detailed view of the novel types of "supramolecular dimers" in 3a (left) and 6b (right). The hydrogen atoms are omitted for clarity, except for the atoms involved in hydrogen bonding (black dashed lines).

\section{DFT calculations}

In order to support our conclusions from magnetochemical analyses of the experimental data, we performed isotropic exchange parameter calculations using the DFT method for $\mathrm{H}$-bond bridged dinuclear molecular fragments $\left[\left\{\mathrm{M}^{\mathrm{III}}(\mathrm{L} 4)\right.\right.$ $\left.\left.\left(\mathrm{H}_{2} \mathrm{O}\right)(\mathrm{NC})\right\}_{2}\right](\mathrm{M}=\mathrm{Fe}, \mathrm{Mn})$ for compounds reported herein, 3a- 
$\mathbf{6 b}$, and also for similar compounds reported in literature, 7a7e. Moreover, we also investigated the role of the diamagnetic nitroprusside anion in mediation of magnetic exchange for compound 4a using the $\left[\left\{\mathrm{Fe}^{\mathrm{III}}(\mathrm{L} 4 \mathrm{c})\left(\mathrm{H}_{2} \mathrm{O}\right)\right\}_{2}\left\{\mu-\mathrm{Fe}^{\mathrm{II}}(\mathrm{CN})_{5}(\mathrm{NO})\right\}\right]$ molecular fragment.

All the calculations were based on experimental X-ray geometries except for 7a, where some hydrogen atoms were missing in the CSD deposited data (CCDC IGAKEG) and their atomic positions were optimized with the BP86 functional and a def2-TZVP(-f) basis set.

As this work extends from our research on magnetic exchange in transition metal complexes containing diamagnetic bridging polythiocyanidoplatinate, ${ }^{14,15}$ the same hybrid functional B3LYP together with a def2-TZVP basis set and the scalar relativistic second-order Douglas-Kroll-Hess Hamiltonian were used.

Therefore, the results of relevant hydrogen bond bridged compounds, $\quad\left[\left\{\mathrm{Mn}(\mathrm{L} 4 \mathrm{o})\left(\mathrm{H}_{2} \mathrm{O}\right)\right\}_{2}\left\{\mu-\mathrm{Pt}(\mathrm{SCN})_{6}\right\}\right] \quad(8), \quad\left[\left\{\mathrm{Mn}(\mathrm{L} 4 \mathrm{n})\left(\mathrm{H}_{2} \mathrm{O}\right)\right\}_{2^{-}}\right.$ $\left.\left\{\mu-\mathrm{Pt}(\mathrm{SCN})_{4}\right\}\right] \quad(\mathbf{9}), \quad\left[\left\{\mathrm{Mn}(\mathrm{L} 4 \mathrm{~b})\left(\mathrm{CH}_{3} \mathrm{OH}\right)\right\}_{2}\left\{\mu-\mathrm{Pt}(\mathrm{SCN})_{4}\right\}\right] \quad$ (10) and $\left[\left\{\mathrm{Mn}(\mathrm{L} 4 \mathrm{p})\left(\mathrm{CH}_{3} \mathrm{OH}\right)\right\}_{2}\left\{\mu-\mathrm{Pt}(\mathrm{SCN})_{4}\right\}\right]$ (11), where $\mathrm{L}_{4} \mathrm{n}^{2-}=N, N^{\prime}-$ benzene-bis(4-aminodiethylenesalicylideneiminate) dianion, ${\mathrm{L} 4 \mathrm{o}^{2-}}^{2-} N, N^{\prime}$-3-methylbenzene-bis(3-ethoxysalicylideneiminate) dianion and $\mathrm{L} 4 \mathrm{p}^{2-}=N, N^{\prime}$-ethylene-bis(naphthylidenebenzeneiminate) dianion, were also included in Table 3.

The isotropic exchange analysis was based on the following Heisenberg spin Hamiltonian

$$
\hat{H}=-J\left(\vec{S}_{1} \cdot \vec{S}_{2}\right)
$$

and evaluation of energy differences between high-spin (HS) and broken-symmetry (BS) spin states, $\Delta=E_{\mathrm{BS}}-E_{\mathrm{HS}}$, using quantum-chemical computational software ORCA. The final $J$-values were calculated by Ruiz's

$$
J^{\text {Ruiz }}=\Delta /\left(2 S_{1} S_{2}+S_{1}\right)
$$

and Yamaguchi's

$$
J^{\mathrm{Yam}}=2 \Delta /\left(\left\langle S^{2}\right\rangle_{\mathrm{HS}}+\left\langle S^{2}\right\rangle_{\mathrm{BS}}\right)
$$

approaches and are tabulated for $\left[\left\{\mathrm{M}^{\mathrm{III}}\left(\mathrm{L}_{\mathrm{i}}\right)\left(\mathrm{H}_{2} \mathrm{O}\right)(\mathrm{NC})\right\}_{2}\right]$ fragments in Table 3. HS spin states had small spin contaminations, manifested by the calculated $\left\langle S^{2}\right\rangle_{\text {HS }}$ values that are close to the theoretical values $\left\langle S^{2}\right\rangle_{\mathrm{HS}}=S(S+1)$ where $S=5$ for $\mathrm{M}=\mathrm{Fe}$ and $S=4$ for $\mathrm{M}=\mathrm{Mn}\left(S_{\mathrm{HS}}\right.$ is the total spin value for the HS state), while the values of the BS spin states $\left\langle S^{2}\right\rangle_{\mathrm{LS}}$ are close to $M_{\mathrm{S}}^{2}+S_{\mathrm{HS}}\left(M_{\mathrm{S}}\right.$ is the spin projection of the BS spin state).

First, the DFT calculation for the $\left[\left\{\mathrm{Fe}^{\mathrm{III}}\left(\mathrm{L}_{3}\right)\left(\mathrm{H}_{2} \mathrm{O}\right)\right\}_{2}\right.$ $\left.\left\{\mu-\mathrm{Fe}^{\mathrm{II}}(\mathrm{CN})_{5}(\mathrm{NO})\right\}\right]$ molecular fragment of $\mathbf{4 a}$ resulted in insignificant magnetic exchange, $J^{\text {Yam }}=+0.031 \mathrm{~cm}^{-1}\left(J^{\text {Ruiz }}=\right.$ $+0.026 \mathrm{~cm}^{-1}$ ), thus supporting our presumption that this superexchange path is very inefficient in promoting magnetic exchange.

Next, the calculation performed for $\mathrm{H}$-bonded dimers $\left[\left\{\mathrm{M}^{\mathrm{III}}(\mathrm{L} 4)\left(\mathrm{H}_{2} \mathrm{O}\right)(\mathrm{NC})\right\}_{2}\right](\mathrm{M}=\mathrm{Fe}, \mathrm{Mn})$ resulted in the $J$-values tabulated in Table 3 . The $J^{\mathrm{Yam}}$-values were found to be in the range from -0.54 to $-0.60 \mathrm{~cm}^{-1}$ for $\left[\left\{\mathrm{Fe}^{\mathrm{III}}(\mathrm{L} 4)\left(\mathrm{H}_{2} \mathrm{O}\right)(\mathrm{NC})\right\}_{2}\right](3 \mathrm{a}$, 4a and 5a), and in the range from -0.56 to $-0.94 \mathrm{~cm}^{-1}$ for
$\left[\left\{\mathrm{Mn}^{\mathrm{III}}(\mathrm{L} 4)\left(\mathrm{H}_{2} \mathrm{O}\right)(\mathrm{NC})\right\}_{2}\right]$ and $\left[\left\{\mathrm{Mn}^{\mathrm{III}}(\mathrm{L} 4)\left(\mathrm{H}_{2} \mathrm{O}\right)(\mathrm{NCS})\right\}_{2}\right](\mathbf{2 b}-\mathbf{6 b}$ and $\mathbf{7 b}-\mathbf{1 1})$. Good agreement between $J$-values derived from magnetochemical analysis of the experimental data and DFT calculations was obtained for compounds $\mathbf{3 a}, \mathbf{4 b}, \mathbf{6 b}$ and $7 \mathbf{b}$, when taking into account the $J^{\text {Yam }}$ values. However, larger discrepancies were observed for the remaining compounds, e.g. in the case of $\mathbf{4 a}$, magnetic analyses resulted in $J_{\text {mag }} \approx$ $-1.0 \mathrm{~cm}^{-1}$, which is in contrast to the values of $J^{\text {Ruiz }}=$ $-0.48 \mathrm{~cm}^{-1}$ or $J^{\text {Yam }}=-0.57 \mathrm{~cm}^{-1}$ (Table 3). The question then arises: why does the same DFT method result in such unequal results upon comparison with the magnetic analysis? We can speculate that these discrepancies are due to small changes in the crystal structures, which may occur at a lower temperature than that used for X-ray analysis. To test this possibility, we performed a constrained geometry optimization for the $\left[\left\{\mathrm{Fe}^{\mathrm{III}}(\mathrm{L} 4 \mathrm{c})\left(\mathrm{H}_{2} \mathrm{O}\right)(\mathrm{NC})\right\}_{2}\right]$ molecular fragment of $\mathbf{4 a}$, where the Fe...Fe distance was varied between 4.4 and $4.9 \AA$ A. The geometry was optimized using the BP86 functional with a def2-TZVP (-f) basis set together with a conductor-like screening model (COSMO), van der Waals corrections (VDW10) and the relativistic effects with the scalar relativistic second-order DouglasKroll-Hess Hamiltonian (DKH2). Afterwards, the $J$-values were calculated at the B3LYP + DKH2/def2-TZVP level of theory for each of the optimized molecular structures to ensure the same condition as that used for the molecular fragments of 3a-11 based on their X-ray structures.

This resulted in the magneto-structural correlation depicted in Fig. 8, from which we can conclude that the antiferromagnetic exchange is increasing with decreasing Fe...Fe separation. However, the change of $\Delta\left(J_{\mathrm{DFT}}\right) / \Delta\left(d_{\mathrm{Fe}-\mathrm{Fe}}\right) \approx$ $0.5-1.0 \mathrm{~cm}^{-1} / \AA$ cannot explain the large discrepancies between
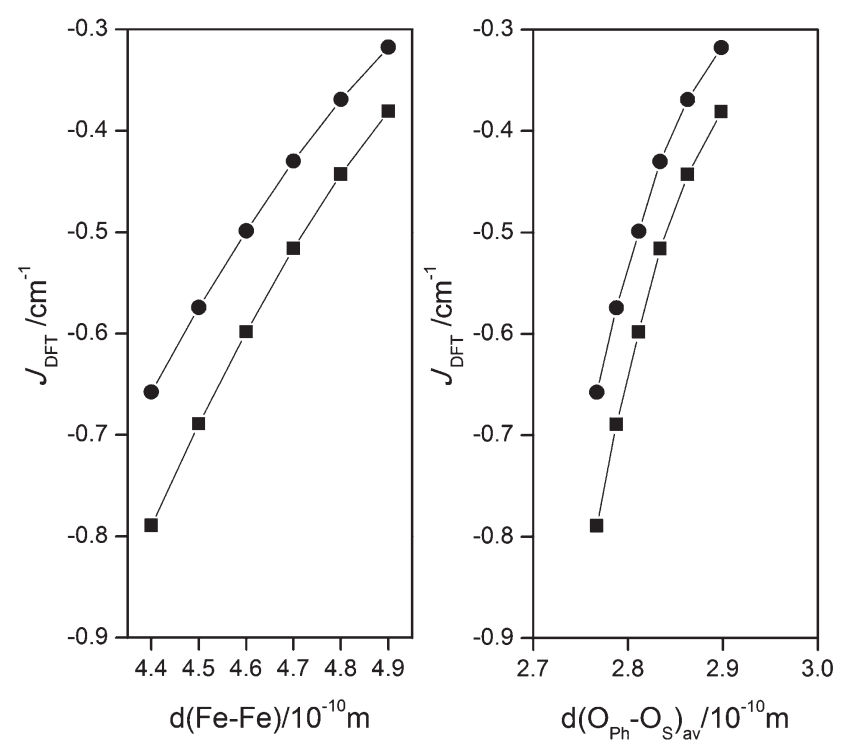

Fig. 8 The calculated isotropic exchange $J^{\text {Ruiz }}$ (circles) and $\mathrm{J}^{\text {Yam }}$ (squares) as a function of the $\mathrm{Fe} \cdots \mathrm{Fe}$ distance (left) and the $\mathrm{O}_{\mathrm{Ph}} \cdots \mathrm{O}_{\mathrm{S}}$ distance (right) in the $\left[\left\{\mathrm{Fe}(\mathrm{L} 4 \mathrm{c})\left(\mathrm{H}_{2} \mathrm{O}\right)(\mathrm{NC})\right\}_{2}\right]$ molecular fragment of $4 \mathrm{a}$ calculated using B3LYP + DKH2/def2-TZVP, while the molecular geometries were optimized using BP86 + COSMO + VDW10 + DKH2/ def2-TZVP(-f). 
$J_{\text {DFT }}$ and $J_{\text {mag }}$ in terms of possible small changes in the crystal structures induced by cooling to a very low temperature.

Thus, we also tested another hypothesis relating to the positions of the hydrogen atoms in the molecular/crystal structure. It is well known that determination of the hydrogen atom positions from X-ray analysis can be potentially inaccurate, especially when the hydrogen atoms are bonded to atoms with high electronegativities such as oxygen or nitrogen atoms. This was also pointed out in several DFT studies devoted to magnetic exchange mediated by hydrogen bonds in other transition metal complexes. ${ }^{29}$ Due to these reasons we have to find out how the positions of hydrogen atoms influence the magnetic exchange interactions. Therefore, the positions of hydrogen atoms involved in magnetic exchange pathways (in $\mathrm{H}$-bond bridged dinuclear molecular fragments $\left[\left\{\mathrm{M}^{\mathrm{III}}(\mathrm{L} 4)\left(\mathrm{H}_{2} \mathrm{O}\right)(\mathrm{NC})\right\}_{2}\right]$ $(\mathrm{M}=\mathrm{Fe}, \mathrm{Mn})(\mathbf{4 a}, \mathbf{5 a}, \mathbf{4 b}, \mathbf{7 a}$, and 7e) and also for [ $\{\mathrm{Mn}(\mathrm{L} 4)-$ $\left.\left.\left(\mathrm{H}_{2} \mathrm{O}\right)(\mathrm{NCS})\right\}_{2}\right]$ (8 and 9), while keeping all other atoms in the same positions as determined from their X-ray structures) were optimized using BP86/def-TZVP(-f). The situation for other complexes, namely $\mathbf{3 a}, \mathbf{6 b}, \mathbf{7 b}$ and $\mathbf{7 d}$, is more complex because water molecules are not only involved in hydrogen bonds between closest metal atoms, but they also form hydrogen bonds to methanol molecules ( $3 \mathbf{a}$ and $7 \mathbf{b}$ ) or to cyanido ligands of the nitroprusside anions from other supramolecular chains ( $6 \mathbf{b}$ and $\mathbf{7 d}$ ), and so they were excluded.

The H-atom geometry optimization procedure for molecular fragments of $\mathbf{4 a}, \mathbf{5 a}, \mathbf{4 b}, \mathbf{7 a}, 7 \mathbf{e}$ and 8-11 generally resulted in an increase in the $\mathrm{O}-\mathrm{H}$ bond lengths, which can be demonstrated using $\mathrm{O}-\mathrm{H}$ distances of water molecules in $4 \mathrm{a}: d(\mathrm{O}-\mathrm{H})_{\mathrm{X} \text {-ray }}=$ 0.831 and $0.837 \AA$ and $d(\mathrm{O}-\mathrm{H})_{\mathrm{DFT}}=0.989$ and $0.994 \AA$ (Fig. 9). In next step, the $J$-values were calculated using B3LYP + DKH2/def2-TZVP and resulted in much larger antiferromagnetic exchange constants (Table 3 ), which can be exemplified again for 4a: $J^{\text {Ruiz }}=-0.81 \mathrm{~cm}^{-1}$ or $J^{\text {Yam }}=-0.98 \mathrm{~cm}^{-1}$ and especially the latter value is almost identical to $J_{\mathrm{mag}} \approx-1.0 \mathrm{~cm}^{-1}$ determined from magnetic analysis.

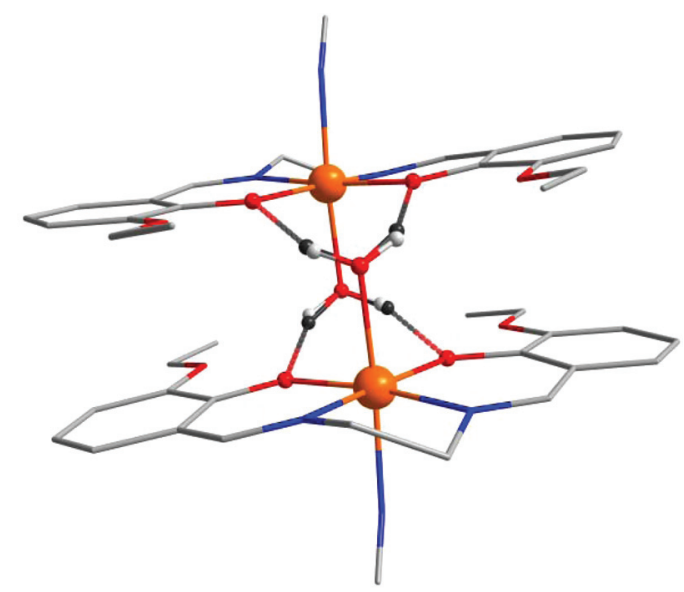

Fig. 9 Molecular fragment $\left[\left\{\mathrm{Fe}(\mathrm{L} 4 \mathrm{c})\left(\mathrm{H}_{2} \mathrm{O}\right)(\mathrm{NC})\right\}_{2}\right]$ of $4 \mathrm{a}$ : comparison of the hydrogen atom positions based on the $\mathrm{X}$-ray structure (light gray balls) and based on geometry optimization using BP86/def2-TZVP(-f) (dark gray balls). All hydrogen atoms not involved in the formation of the supramolecular dimer were omitted for clarity.
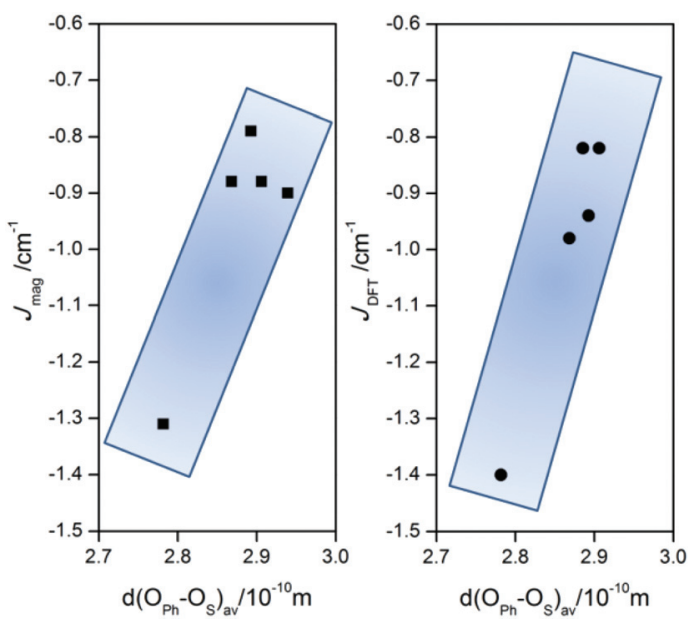

Fig. 10 Isotropic exchange $J$-values as a function of average $\mathrm{O}_{\mathrm{Ph}} \cdots \mathrm{O}_{\mathrm{S}}$ distances in $\mathrm{Mn}(\mathrm{II})$ compounds $4 \mathrm{~b}, 7 \mathrm{7}, 7 \mathrm{7}, 8$ and 9, either derived from magnetic analysis (left) or calculated by DFT using B3LYP + DKH2/def2TZVP on geometries in which only the hydrogen atoms were optimized using BP86/def2-TZVP(-f) (right).

These results demonstrate much larger sensitivity of the magnetic exchange towards the position of the hydrogen atom within the $\mathrm{O}-\mathrm{H} \cdots \mathrm{O}$ hydrogen bond than towards the $\mathrm{M} \cdots \mathrm{M}$ distance, which can explain some discrepancies observed between $J$-values derived from magnetic analyses and DFT calculations based on X-ray molecular structures. Furthermore, there is clear evidence that the $J$-values correlate with average $\mathrm{O}_{\mathrm{Ph}} \cdots \mathrm{O}_{\mathrm{S}}$ distances both in $\mathrm{Fe}(\mathrm{III})$ and $\mathrm{Mn}$ (III) complexes, as demonstrated in Fig. 8 and 10, respectively.

\section{Experimental section}

\section{Materials}

All the starting chemicals were of analytical reagent grade and were used as received. $\mathrm{FeCl}_{3} \cdot 6 \mathrm{H}_{2} \mathrm{O}, \mathrm{MnCl}_{2} \cdot 4 \mathrm{H}_{2} \mathrm{O}, \mathrm{Na}_{2}[\mathrm{Fe}-$ $\left.(\mathrm{CN})_{5} \mathrm{NO}\right] \cdot 2 \mathrm{H}_{2} \mathrm{O}$, solvents and the organic compounds 1,2-diaminocyclohexane, 1,2-diamino-benzene, ethane-1,2-diamine, propane-1,2-diamine, 2-hydroxy-benzaldehyde, 4-hydroxy-1naphthaldehyde, 3-ethoxy-2-hydroxybenzaldehyde and triethylamine $\left(\mathrm{Et}_{3} \mathrm{~N}\right)$ were obtained from commercial sources (SigmaAldrich Co., Acros Organics Co., Lachema Co. and Fluka Co.).

\section{Synthesis of the tetradentate Schiff bases $\mathrm{H}_{2} \mathrm{~L} 4 \mathrm{a}-\mathrm{H}_{2} \mathrm{~L} 4 \mathrm{e}$}

These organic compounds were prepared by Schiff base condensations between the following derivatives, i.e. 2-hydroxybenzaldehyde $\left(\mathrm{H}_{2} \mathrm{~L} 4 \mathrm{a}\right.$ or $\left.\mathrm{H}_{2} \mathrm{~L} 4 \mathrm{c}\right)$, 2-hydroxy-1-naphthaldehyde $\left(\mathrm{H}_{2} \mathrm{~L} 4 \mathrm{e}\right)$ or 3-ethoxy-2-hydroxybenzaldehyde $\left(\mathrm{H}_{2} \mathrm{~L} 4 \mathrm{~b}\right.$ or $\left.\mathrm{H}_{2} \mathrm{~L} 4 \mathrm{~d}\right)$ and the corresponding diamines, i.e. 1,2-diaminocyclohexane $\left(\mathrm{H}_{2} \mathrm{~L} 4 \mathrm{a}\right)$, 1,2-diaminobenzene $\left(\mathrm{H}_{2} \mathrm{~L} 4 \mathrm{~b}\right.$ or $\left.\mathrm{H}_{2} \mathrm{~L} 4 \mathrm{e}\right)$, ethane-1,2diamine $\left(\mathrm{H}_{2} \mathrm{~L} 4 \mathrm{c}\right)$ or propane-1,2-diamine $\left(\mathrm{H}_{2} \mathrm{~L} 4 \mathrm{~d}\right)$. Methanol solutions of benzaldehyde derivatives $(5 \mathrm{mmol}$ in $20 \mathrm{~mL}$ ) and respective diamines $(2.5 \mathrm{mmol}$ in $10 \mathrm{~mL})$ were stirred under reflux at $40{ }^{\circ} \mathrm{C}$ for 2 hours, resulting in yellow powder materials after evaporation of the solvent. The solid powdered 
substances were washed with diethyl ether and dried in a vacuum; yields were higher than $97 \%$.

Synthesis of the precursors $[\mathrm{Fe}(\mathrm{L4a}) \mathrm{Cl}](1 \mathrm{a})[\mathrm{Mn}(\mathrm{L4a}) \mathrm{Cl}](1 \mathrm{~b})$, [Fe(L4b)Cl] (1c), [Fe(L4c)Cl] (1d), [Mn(L4c)Cl] (1e), [Fe(L4d)Cl] (1f) and [Mn(L4e)Cl] (1g)

A solution of $10 \mathrm{mmol}$ of $\mathrm{FeCl}_{3} \cdot 6 \mathrm{H}_{2} \mathrm{O}$ or $\mathrm{MnCl}_{2} \cdot 4 \mathrm{H}_{2} \mathrm{O}$ in $10 \mathrm{~mL}$ of methanol was added to a solution of $10 \mathrm{mmol}$ of $\mathrm{H}_{2} \mathrm{~L} 4 \mathrm{a}-$ $\mathrm{H}_{2} \mathrm{~L} 4 \mathrm{e}$ in $20 \mathrm{~mL}$ of ethanol. The mixture was stirred for $10 \mathrm{~min}$, and then $20 \mathrm{mmol}$ of triethylamine in ethanol $(10 \mathrm{~mL})$ was added. The resulting solution was refluxed for $2 \mathrm{~h}$, then after cooling, diethyl ether was added, which resulted in precipitation of a black or a brown powder. The solid was filtered off, washed with diethyl ether and dried in a vacuum; yields were higher than $90 \%$.

\section{Synthesis of the complexes $2 a-6 b$}

The dark-brown crystals or dark powders of complexes $\mathbf{2 a - 6 b}$ were obtained from a methanol solution $(40 \mathrm{~mL})$ of complexes $1 \mathrm{a}-1 \mathrm{~g}(0.2 \mathrm{mmol})$ combined with a methanol-water mixture $(1: 1)$ of $\mathrm{Na}_{2}\left[\mathrm{Fe}(\mathrm{CN})_{5}(\mathrm{NO})\right] \cdot 2 \mathrm{H}_{2} \mathrm{O}(0.1 \mathrm{mmol})$. The solutions were stirred at room temperature for $4 \mathrm{~h}$. Slow evaporation of the resulting solutions at room temperature afforded the complexes as black single crystals suitable for X-ray diffraction after a week. Black crystals were filtered off, washed twice with water and diethyl ether and dried in a vacuum.

$\left[\left\{\mathbf{F e}(\mathbf{L 4 a})\left(\mathrm{H}_{2} \mathrm{O}\right)\right\}_{2}\left\{\boldsymbol{\mu}-\mathrm{Fe}(\mathrm{CN})_{5}(\mathrm{NO})\right\}\right] \cdot \mathrm{CH}_{3} \mathrm{OH}$ (2a). Yield: $76 \%$, Anal. calcd for $\mathrm{C}_{46} \mathrm{H}_{48} \mathrm{~N}_{10} \mathrm{O}_{8} \mathrm{Fe}_{3}$ : C, 53.30; H, 4.66; N, 13.51. Found: C, 53.52; H, 4.53; N, 13.70\%. $\Lambda_{\mathrm{M}}\left(\mathrm{DMF}, \mathrm{S} \mathrm{cm} \mathrm{mol}^{-1}\right)$ : 5.2. FT-IR (Nujol, $\mathrm{cm}^{-1}$ ): 517m; 486m; 474m; 444m; 431w; 369s; 342m; 329m; 296m $\nu(\mathrm{Fe}-\mathrm{N}) ; 275 \mathrm{w} ; 245 \mathrm{w} \nu(\mathrm{Fe}-\mathrm{O}) ; 236 \mathrm{~m}$; 185w; 174w. FT-IR (KBr, $\left.\mathrm{cm}^{-1}\right): 3115 \mathrm{w} ; 3037 \mathrm{w} \nu(\mathrm{C}-\mathrm{H})_{\mathrm{ar}}$; $2872 \mathrm{w}$; $2987 \mathrm{w} \nu(\mathrm{C}-\mathrm{H})_{\text {alip }} ; 2939 \mathrm{w} \nu(\mathrm{C}-\mathrm{H})_{\text {alip }} ; 2152 \mathrm{~m} \nu(\mathrm{C} \equiv \mathrm{N}) ; 1917 \mathrm{~m}$ $\nu(\mathrm{N}=\mathrm{O}) ; 1625 \mathrm{vs} \nu(\mathrm{C}=\mathrm{N})_{\mathrm{ar}} ; 1595 \mathrm{~m} ; 1541 \mathrm{~m} ; 1472 \mathrm{~m} \nu(\mathrm{C}=\mathrm{C})_{\mathrm{ar}}$; $1452 \mathrm{vs} \nu(\mathrm{C}=\mathrm{C})_{\mathrm{ar}} ; 1357 \mathrm{w} ; 1274 \mathrm{w} ; 1222 \mathrm{w} ; 1193 \mathrm{w} ; 1157 \mathrm{w} ; 1114 \mathrm{w}$; 1110w; 1039w; 1018w; 945w; 858w; 752m.

$\left[\left\{\mathbf{M n}(\mathbf{L} 4 a)\left(\mathbf{H}_{2} \mathrm{O}\right)\right\}_{2}\left\{\boldsymbol{\mu}-\mathrm{Fe}(\mathbf{C N})_{5}(\mathbf{N O})\right\}\right] \cdot \mathrm{CH}_{3} \mathrm{OH}(\mathbf{2 b})$. Yield: $75 \%$, Anal. calcd for $\mathrm{C}_{46} \mathrm{H}_{48} \mathrm{~N}_{10} \mathrm{O}_{8} \mathrm{Mn}_{2} \mathrm{Fe}_{1}$ : C, 53.39; H, 4.67; N, 13.53. Found: C, 53.54; H, 4.57; N, 13.74\%. $\Lambda_{\mathrm{M}}$ (DMF, $\mathrm{S} \mathrm{cm}^{2}$ $\mathrm{mol}^{-1}$ ): 11.5. FT-IR (Nujol, $\mathrm{cm}^{-1}$ ): 572w; 539w; 510w; 468m; $455 \mathrm{w} ; 438 \mathrm{w} ; 419 \mathrm{w} ; 379 \mathrm{~m} ; 333 \mathrm{w} ; 322 \mathrm{w} ; 286 \mathrm{~m} \nu(\mathrm{Mn}-\mathrm{N}) ; 259 \mathrm{w}$ $\nu(\mathrm{Mn}-\mathrm{O})$; 209w. FT-IR $\left(\mathrm{KBr}, \mathrm{cm}^{-1}\right): 3132 \mathrm{w} ; 3021 \mathrm{w} \nu(\mathrm{C}-\mathrm{H})_{\mathrm{ar}}$; $2931 \mathrm{w} \nu(\mathrm{C}-\mathrm{H})_{\text {alip }} ; 2859 \mathrm{w} ; 2163 \mathrm{~m} \nu(\mathrm{C} \equiv \mathrm{N}) ; 1922 \mathrm{~m} \nu(\mathrm{N}=\mathrm{O})$; $1618 \mathrm{vs} \nu(\mathrm{C}=\mathrm{N})_{\mathrm{ar}} ; 1596 \mathrm{~m} ; 1544 \mathrm{~m} ; 1468 \mathrm{~m} \nu(\mathrm{C}=\mathrm{C})_{\mathrm{ar}} ; 1443 \mathrm{~m}$ $\nu(\mathrm{C}=\mathrm{C})_{\mathrm{ar}} ; 1395 \mathrm{w} ; 1307 \mathrm{w} ; 1286 \mathrm{w} ; 1268 \mathrm{w} ; 1233 \mathrm{w} ; 1196 \mathrm{w} ; 1148 \mathrm{w}$; 1052w; 1006w; 995w; 907w; 851w; 753m; 677w.

$\left[\left\{\mathrm{Fe}(\mathrm{L} 4 \mathrm{~b})\left(\mathrm{H}_{2} \mathrm{O}\right)\right\}_{2}\left\{\boldsymbol{\mu}-\mathrm{Fe}(\mathrm{CN})_{5}(\mathrm{NO})\right\}\right] \cdot 2 \mathrm{CH}_{3} \mathrm{OH}$ (3a). Yield: $71 \%$, Anal. calcd for $\mathrm{C}_{47} \mathrm{H}_{40} \mathrm{~N}_{10} \mathrm{O}_{9} \mathrm{Fe}_{3}: \mathrm{C}, 53.43 ; \mathrm{H}, 3.81 ; \mathrm{N}, 13.25$. Found: C, 53.56; H, 3.52; N, 13.71\%. $\Lambda_{\mathrm{M}}\left(\mathrm{DMF}, \mathrm{S} \mathrm{cm}^{2} \mathrm{~mol}^{-1}\right.$ ): 15.2. FT-IR (Nujol, $\mathrm{cm}^{-1}$ ): 568w; 554w; 515w; 491w; 460m; 426w; 390w; 352m; 332w; 306w; 285m $\nu(\mathrm{Fe}-\mathrm{N}) ; 267 \mathrm{w} ; 241 \mathrm{~m}$ $\nu(\mathrm{Fe}-\mathrm{O}) ; 217 \mathrm{w} ; 198 \mathrm{w}$. FT-IR $\left(\mathrm{KBr}, \mathrm{cm}^{-1}\right): 3372 \mathrm{w} ; 3299 \mathrm{w} ; 3217 \mathrm{w}$; $3118 \mathrm{w} ; 3025 \mathrm{w} \nu(\mathrm{C}-\mathrm{H})_{\mathrm{ar}} ; 2932 \mathrm{w} \nu(\mathrm{C}-\mathrm{H})_{\mathrm{alip}} ; 2139 \mathrm{~m} \nu(\mathrm{C} \equiv \mathrm{N})$; $1906 \mathrm{~m} \nu(\mathrm{N}=\mathrm{O})$; 1613vs $\nu(\mathrm{C}=\mathrm{N})_{\mathrm{ar}} ; 1539 \mathrm{~m} ; 1467 \mathrm{~m} \nu(\mathrm{C}=\mathrm{C})_{\mathrm{ar}}$; $1446 \mathrm{~m} \nu(\mathrm{C}=\mathrm{C})_{\mathrm{ar}} ; 1398 \mathrm{w} ; 1314 \mathrm{~m} ; 1268 \mathrm{w} ; 1230 \mathrm{w} ; 1023 \mathrm{w} ; 997 \mathrm{w}$; 904w; 809w; 753m; 661w.
$\left[\left\{\mathbf{F e}(\mathbf{L} 4 \mathbf{c})\left(\mathrm{H}_{2} \mathbf{O}\right)\right\}_{2}\left\{\boldsymbol{\mu}-\mathrm{Fe}(\mathrm{CN})_{5}(\mathrm{NO})\right\}\right] \quad$ (4a). Yield: $\quad 72 \%$ Anal. calcd for $\mathrm{C}_{45} \mathrm{H}_{48} \mathrm{~N}_{10} \mathrm{O}_{11} \mathrm{Fe}_{3}$ : C, 50.39; $\mathrm{H}, 4.51 ; \mathrm{N}, 13.06$. Found: C, $50.52 ; \mathrm{H}, 4.69 ; \mathrm{N}, 13.33 \% . \Lambda_{\mathrm{M}}$ (DMF, $\mathrm{S} \mathrm{cm} \mathrm{mol}^{-1}$ ): 21.8 . FT-IR (Nujol, $\mathrm{cm}^{-1}$ ): 508m; 492m; 475m; 446w; 437w; 372vs; $344 \mathrm{~m} ; 318 \mathrm{~m} ; 288 \mathrm{w} \nu(\mathrm{Fe}-\mathrm{N}) ; 248 \mathrm{~m} \nu(\mathrm{Fe}-\mathrm{O}) ; 224 \mathrm{w} ; 170 \mathrm{w}$. FT-IR $\left(\mathrm{KBr}, \mathrm{cm}^{-1}\right): 3445 \mathrm{w} ; 3414 \mathrm{w} ; 3047 \mathrm{w} \nu(\mathrm{C}-\mathrm{H})_{\mathrm{ar}} ; 2992 \mathrm{w} \nu(\mathrm{C}-\mathrm{H})_{\mathrm{alip}}$; $2942 \mathrm{w} \nu(\mathrm{C}-\mathrm{H})_{\mathrm{alip}} ; 2882 \mathrm{w} ; 2141 \mathrm{~m} \nu(\mathrm{C} \equiv \mathrm{N}) ; 1882 \mathrm{vs} \nu(\mathrm{N}=\mathrm{O})$; $1616 \mathrm{vs} \nu(\mathrm{C}=\mathrm{N}) ; 1581 \mathrm{~m} ; 1552 \mathrm{~m} ; 1468 \mathrm{~m} \nu(\mathrm{C}=\mathrm{C})_{\mathrm{ar}} ; 1437 \mathrm{~m}$ $\nu(\mathrm{C}=\mathrm{C})_{\mathrm{ar}} ; 1395 \mathrm{w} ; 1347 \mathrm{w} ; 1295 \mathrm{~m} ; 1250 \mathrm{~m} ; 1211 \mathrm{w} ; 1174 \mathrm{w}$; $1141 \mathrm{w} ; 1112 \mathrm{w} ; 1074 \mathrm{~m} ; 1055 \mathrm{w} ; 1021 \mathrm{w} ; 947 \mathrm{w} ; 857 \mathrm{w} ; 841 \mathrm{w} ;$ 774w; 732w; 692w.

[\{Mn(L4c) $\left.\left.\left(\mathrm{H}_{2} \mathbf{O}\right)\right\}_{2}\left\{\boldsymbol{\mu}-\mathrm{Fe}(\mathbf{C N})_{5}(\mathbf{N O})\right\}\right] \quad(\mathbf{4 b})$. Yield: $65 \%$ Anal. calcd for $\mathrm{C}_{45} \mathrm{H}_{48} \mathrm{~N}_{10} \mathrm{O}_{11} \mathrm{Mn}_{2} \mathrm{Fe}_{1}$ : C, 50.48; $\mathrm{H}, 4.51 ; \mathrm{N}, 13.08$. Found: C, 50.55; H, 4.64; N, 13.27\%. $\Lambda_{\mathrm{M}}\left(\mathrm{DMF}, \mathrm{S} \mathrm{cm}^{2} \mathrm{~mol}^{-1}\right)$ : 16.5. FT-IR (Nujol, $\mathrm{cm}^{-1}$ ): 515m; 491m;469m; 452m; 429w; 378s; 351m; 311m $\nu$ (Mn-N); 254w $\nu$ (Mn-O); 239m; 170w. FT-IR $\left(\mathrm{KBr}, \mathrm{cm}^{-1}\right): 3443 \mathrm{w} ; 3412 \mathrm{w} ; 3072 \mathrm{w} \nu(\mathrm{C}-\mathrm{H})_{\mathrm{ar}} ; 3056 \mathrm{w} \nu(\mathrm{C}-\mathrm{H})_{\mathrm{ar}}$; $2996 \mathrm{w} \nu(\mathrm{C}-\mathrm{H})_{\mathrm{alip}} ; 2926 \mathrm{w} \nu(\mathrm{C}-\mathrm{H})_{\mathrm{alip}} ; 2877 \mathrm{w} ; 2138 \mathrm{~m} \nu(\mathrm{C} \equiv \mathrm{N})$; $1874 \mathrm{vs} \quad \nu(\mathrm{N}=\mathrm{O})$; 1614vs $\nu(\mathrm{C}=\mathrm{N}) ; 1579 \mathrm{~m} ; 1550 \mathrm{~m} ; 1465 \mathrm{~m}$ $\nu(\mathrm{C}=\mathrm{C})_{\mathrm{ar}} ; 1438 \mathrm{~m} \nu(\mathrm{C}=\mathrm{C})_{\mathrm{ar}} ; 1393 \mathrm{w} ; 1346 \mathrm{w} ; 1298 \mathrm{~m} ; 1254 \mathrm{~m}$; $1216 \mathrm{w} ; 1178 \mathrm{w} ; 1153 \mathrm{w} ; 1108 \mathrm{w} ; 1083 \mathrm{~m} ; 1050 \mathrm{w} ; 1018 \mathrm{w} ; 953 \mathrm{w}$; 894w; 843w; 779w; 763w; 732m; 690w; 603m.

$\left[\left\{\mathbf{F e}(\mathbf{L} 4 \mathrm{~d})\left(\mathbf{H}_{2} \mathbf{O}\right)\right\}_{2}\left\{\boldsymbol{\mu}-\mathrm{Fe}(\mathbf{C N})_{5}(\mathbf{N O})\right\}\right] \quad$ (5a). Yield: $70 \%$ Anal. calcd for $\mathrm{C}_{47} \mathrm{H}_{52} \mathrm{~N}_{10} \mathrm{O}_{11} \mathrm{Fe}_{3}$ : C, 51.29; H, 4.76; N, 12.72. Found: C, $50.91 ; \mathrm{H}, 4.55 ; \mathrm{N}, 12.54 \% . \Lambda_{\mathrm{M}}\left(\mathrm{DMF}, \mathrm{S} \mathrm{cm} \mathrm{mol}^{-1}\right)$ : 14.2. FT-IR (Nujol, $\mathrm{cm}^{-1}$ ): 518m; 489m; 452m; 449m; 431w; 354s; 303m; 284m $\nu(\mathrm{Fe}-\mathrm{N}) ; 276 \mathrm{w} ; 246 \mathrm{w} \nu(\mathrm{Fe}-\mathrm{O}) ; 241 \mathrm{~m}$. FT-IR (KBr, $\left.\mathrm{cm}^{-1}\right)$ : 3348w; 3268w; 3061w $\nu(\mathrm{C}-\mathrm{H})_{\mathrm{ar}} ; 2981 \mathrm{w} \nu(\mathrm{C}-\mathrm{H})_{\mathrm{alip}} ; 2930 \mathrm{w}$ $\nu(\mathrm{C}-\mathrm{H})_{\text {alip }}$; 2880w; 2149s $\nu(\mathrm{C} \equiv \mathrm{N})$; 1882vs $\nu(\mathrm{N}=\mathrm{O})$; 1616vs $\nu(\mathrm{C}=\mathrm{N}) ; 1594 \mathrm{~s} ; 1552 \mathrm{~m} ; 1463 \mathrm{~m} \nu(\mathrm{C}=\mathrm{C})_{\mathrm{ar}} ; 1443 \mathrm{vs} \nu(\mathrm{C}=\mathrm{C})_{\mathrm{ar}}$; $1391 \mathrm{~m} ; 1345 \mathrm{w} ; 1322 \mathrm{w} ; 1295 \mathrm{~m} ; 1250 \mathrm{~m} ; 1218 \mathrm{~m} ; 1180 \mathrm{w} ; 1110 \mathrm{w}$; 1076w; 1037w; 1014w; 895w; 850w; 762w; 731m; 605w.

$\left[\left\{\mathrm{Mn}(\mathrm{L} 4 \mathrm{e})\left(\mathrm{H}_{2} \mathrm{O}\right)\left(\mathrm{CH}_{3} \mathrm{OH}\right)\right]\left[\left\{\mathrm{Mn}(\mathrm{L4e})\left(\mathrm{H}_{2} \mathrm{O}\right)\right\}\left\{\boldsymbol{\mu}-\mathrm{Fe}(\mathrm{CN})_{5}(\mathrm{NO})\right\}\right]\right.$. $\mathrm{H}_{2} \mathbf{O} \cdot \mathrm{CH}_{3} \mathrm{OH}$ (6b). Yield: $63 \%$ Anal. calcd for $\mathrm{C}_{63} \mathrm{H}_{49} \mathrm{~N}_{10} \mathrm{O}_{10} \mathrm{Mn}_{2} \mathrm{Fe}_{1}$ : C, 59.44; H, 3.95; N, 11.00. Found: C, 59.58; H, 3.66; N, 11.27\%. $\Lambda_{\mathrm{M}}\left(\mathrm{DMF}, \mathrm{S} \mathrm{cm} \mathrm{mol}^{-1}\right.$ ): 91.2. FTFT-IR (Nujol, $\mathrm{cm}^{-1}$ ): 525m; 492m; 453m; 447m; 434w; 355s; 351m; 305m 278m $\nu$ (Mn-N); 248w; 233m $\nu$ (Mn-O); 213w. FT-IR $\left(\mathrm{KBr}, \mathrm{cm}^{-1}\right): 3457 \mathrm{~m} ; 3398 \mathrm{w} ; 3074 \mathrm{w} \nu(\mathrm{C}-\mathrm{H})_{\mathrm{ar}} ; 2987 \mathrm{w} \nu(\mathrm{C}-\mathrm{H})_{\mathrm{alip}}$; $2978 \mathrm{w} \nu(\mathrm{C}-\mathrm{H})_{\text {alip }} ; 2875 \mathrm{w} ; 2152 \mathrm{~s} \nu(\mathrm{C} \equiv \mathrm{N}) ; 1886 \mathrm{vs} \nu(\mathrm{N}=\mathrm{O}) ; 1614 \mathrm{vs}$ $\nu(\mathrm{C}=\mathrm{N}) ; 1587 \mathrm{~s} ; 1549 \mathrm{~m} ; 1474 \mathrm{~m} \nu(\mathrm{C}=\mathrm{C})_{\mathrm{ar}} ; 1454 \mathrm{vs} \nu(\mathrm{C}=\mathrm{C})_{\mathrm{ar}}$; $1387 \mathrm{~m} ; 1332 \mathrm{w} ; 1319 \mathrm{w} ; 1287 \mathrm{~m} ; 1245 \mathrm{~m} ; 1217 \mathrm{~m} ; 1184 \mathrm{w} ; 1122 \mathrm{w}$; 1097w; 1017w; 889w; 867w; 787w; 745 m; 645w.

\section{General methods}

Elemental analysis (CHNS) was performed on a FLASH 2000 CHNS Analyzer (ThermoFisher Scientific). Infrared spectra of the complexes were recorded on a ThermoNicolet NEXUS 670 FT-IR spectrometer using the $\mathrm{KBr}$ technique on a diamond plate in the range $400-4000 \mathrm{~cm}^{-1}$ and Nujol techniques in the range $150-600 \mathrm{~cm}^{-1}$. Thermogravimetric (TG) and differential thermal analyses (DTA) were measured on an Exstar TG/DTA 6200 thermal analyzer (Seiko Instruments Inc.). TG/DTA studies were performed in ceramic pans from room temperature to $850{ }^{\circ} \mathrm{C}$ with a $2.5^{\circ} \mathrm{C} \mathrm{min}{ }^{-1}$ temperature gradient in a dynamic air atmosphere $\left(100 \mathrm{~mL} \mathrm{~min}^{-1}\right)$. 


\section{Single-crystal X-ray analysis details}

X-ray measurements on the selected crystals of $\mathbf{3 a - 6 b}$ were performed on an Oxford Diffraction Xcalibur ${ }^{\mathrm{TM} 2}$ equipped with a Sapphire2 CCD detector using Mo-K $\alpha$ radiation at $100 \mathrm{~K}$. The CrysAlis program package (version 1.171.33.52, Oxford Diffraction) was used for data collection and reduction. ${ }^{34}$ The molecular structures were solved by direct methods SHELX-97 and all non-hydrogen atoms were refined anisotropically on $F^{2}$ using full-matrix least-squares procedure SHELXS-97. ${ }^{35}$ All the hydrogen atoms were found in differential Fourier maps and their parameters were refined using a riding model with $U_{\text {iso }}(\mathrm{H})=1.2\left(\mathrm{CH}, \mathrm{CH}_{2}, \mathrm{OH}\right)$ or $1.5\left(\mathrm{CH}_{3}\right) U_{\text {eq }}$. Non-routine aspects of the structure refinements are as follows: in compounds $\mathbf{3 a}, \mathbf{4 a}, \mathbf{5} \mathbf{a}$ and $\mathbf{6 b}$ the Fe atom of the nitroprusside lies at the inversion center with disorder of the nitrosyl and cyanido groups in two trans positions. Occupation factors for both disordered parts were set to 0.5 .

\section{DFT calculations}

The theoretical calculations were done with the ORCA 2.9.1 computational package. ${ }^{36 a}$ The magnetic exchange $(J)$ was calculated using the hybrid B3LYP functional. ${ }^{36 b-e}$ The brokensymmetry (BS) spin state was generated by the "Flip-Spin" feature of the ORCA program and the isotropic exchange constants $J$ were calculated both by Ruiz's formula ${ }^{37}$ and the Yamaguchi approach. ${ }^{38}$ The polarized triple- $\zeta$ quality basis set (def2-TZVP) proposed by Ahlrichs and co-workers were used for all atoms. ${ }^{39}$ The relativistic effects were dealt with using the scalar relativistic second-order Douglas-Kroll-Hess Hamiltonian (DKH2) together with a relativistically recontracted version of the def2-TZVP basis set. ${ }^{40}$ The calculations utilized the RI approximation with the decontracted auxiliary def2TZVP/J Coulomb fitting basis set and the chain-of-spheres (RIJCOSX) approximation to exact exchange ${ }^{41}$ as implemented in ORCA. Increased integration grids (Grid5 and Gridx5 in ORCA convention) and tight SCF convergence criteria were used in all calculations. The geometry optimization of molecular fragment $\left[\left\{\mathrm{Fe}\left(\mathrm{L}_{3}\right)\left(\mathrm{H}_{2} \mathrm{O}\right)(\mathrm{NC})\right\}_{2}\right](\mathbf{4 a})$ was done using the BP86 functional ${ }^{42}$ with the def2-TZVP(-f) basis set together with the conductor-like screening model (COSMO), ${ }^{43}$ van der Waals corrections (VDW10) ${ }^{44}$ and DKH2. The positions of hydrogen atoms in $\mathrm{H}$-bond bridged dinuclear molecular fragments $\left[\left\{\mathrm{M}^{\mathrm{III}}(\mathrm{L} 4)\left(\mathrm{H}_{2} \mathrm{O}\right)(\mathrm{NC})\right\}_{2}\right](\mathrm{M}=\mathrm{Fe}, \mathrm{Mn})(\mathbf{4 a}, \mathbf{5 a}, \mathbf{4 b}, 7 \mathbf{a}$ and 7e) and also for $\left[\left\{\mathrm{Mn}(\mathrm{L} 4)\left(\mathrm{H}_{2} \mathrm{O}\right)(\mathrm{NCS})\right\}_{2}\right]$ (8 and 9) were calculated again with $\mathrm{BP} 86 / \mathrm{de} 2-\mathrm{TZVP}(-\mathrm{f})$.

\section{Conclusions}

We have reported the synthesis of trinuclear iron(III) and manganese(III) (2a-5a) and dinuclear manganese(III) (6b) Schiff base complexes utilizing the nitroprusside anion, $\left[\mathrm{Fe}^{\mathrm{II}}(\mathrm{CN})_{5} \mathrm{NO}\right]^{2-}$, as a building block. The compounds were characterized by various physical methods (elemental analysis, FT-IR, TG/DTA, single-crystal X-ray analysis), which clearly confirmed their compositions and molecular/crystal structures. It was observed that coordinated water molecules are responsible for the formation of supramolecular 1D chains (3a-5a) or supramolecular dimers (6b) through $\mathrm{O}-\mathrm{H} \cdots \mathrm{O}$ type hydrogen bonds. Thorough magnetic analysis, which consisted of the concurrent fitting of temperature and field dependent powder magnetic data, played an important role in properly identifying values of the isotropic exchange $J$-parameters and zerofield splitting $D$-parameters.

This enabled us, in harmony with DFT calculations of $J$ parameters, to confirm weak antiferromagnetic exchange $(J \approx$ -0.5 to $-1.3 \mathrm{~cm}^{-1}$ ) between metal atoms mediated by $\mathrm{O}-\mathrm{H} \cdots \mathrm{O}$ hydrogen bonds, while the super-exchange path through the diamagnetic nitroprusside anion was found to be negligible. Moreover, a detailed DFT study was performed to explain some discrepancies between $J$-values derived from magnetic analysis and DFT calculations themselves. We demonstrated that such DFT calculations are very sensitive to the position of the hydrogen atoms within the $\mathrm{O}-\mathrm{H} \cdots \mathrm{O}$ hydrogen bond forming a super-exchange pathway. To summarize, the strength of the magnetic exchange in this class of complexes is controlled by the number of $\mathrm{O}_{\mathrm{S}}-\mathrm{H} \cdots \mathrm{O}_{\mathrm{Ph}}$ hydrogen bonds between metal atoms and by the $\mathrm{O}_{\mathrm{S}} \cdots \mathrm{O}_{\mathrm{Ph}}$ distance between the phenolic oxygen atom of the salen-type ligand $\left(\mathrm{O}_{\mathrm{Ph}}\right)$ and the oxygen atom of solvent (water, methanol) molecules coordinated to the neighbouring metal atom $\left(\mathrm{O}_{\mathrm{S}}\right)$. These results help to understand magnetic exchange interactions through hydrogen bonding within supramolecular $\left[\mathrm{M}^{\mathrm{III}}(\mathrm{L} 4)(\text { Solv })\right]^{+} \ldots$ $\left[\mathrm{M}^{\mathrm{III}}(\mathrm{L} 4)(\mathrm{Solv})\right]^{+}$dimers and they might be useful for estimating the strength of such interactions in more magnetically complicated systems (e.g. systems with paramagnetic bridging complexes or systems possessing magnetic ordering or slowrelaxation of magnetization).

\section{Acknowledgements}

We acknowledge the financial support from the Czech Science Foundation (GAČR P207/11/0841), the Operational Program Research and Development for Innovations - European Regional Development Fund (CZ.1.05/2.1.00/03.0058) of the Ministry of Education, Youth and Sports of the Czech Republic, and Palacký University (PrF_2013_015 a 2014009). The authors would like to thank Dr Radka Křikavová for infrared spectroscopy measurements.

\section{Notes and references}

1 (a) C. Chappert, A. Fert and F. N. Van Dau, Nat. Mater., 2007, 6, 813; (b) L. Bogani and W. Wernsdorfer, Nat. Mater., 2008, 7, 179; (c) C. Felser, G. H. Fecher and B. Balke, Angew. Chem., Int. Ed., 2007, 46, 668; (d) W. Wernsdorfer, Nat. Nanotechnol., 2009, 4, 145.

2 (a) V. H. Crawford, H. W. Richardson, J. R. Wasson, D. J. Hodgson and W. E. Hatfield, Inorg. Chem., 1976, 15, 2107; (b) J. Glerup, D. J. Hodgson and E. Pedersen, Acta Chem. Scand., 1983, 37, 161; (c) S. M. Gorun and 
S. J. Lippard, Inorg. Chem., 1991, 30, 1625; (d) N. A. Law, J. W. Kampf and V. L. Pecoraro, Inorg. Chim. Acta, 2000, 297, 252.

3 M. Ding, B. Wang, Z. Wang, J. Zhang, O. Fuhr, D. Fenske and S. Gao, Chem. - Eur. J., 2012, 18, 915.

4 (a) J. Larionova, S. A. Chavan, J. V. Yakhmi, A. G. Frøystein, J. Sletten, C. Sourisseau and O. Kahn, Inorg. Chem., 1997, 36, 6374; (b) O. Kahn, J. Larionova and J. V. Yakhmi, Chem. Eur. J., 1999, 5, 3443; (c) R. Herchel, J. Tuček, Z. Trávníček, D. Petridis and R. Zbořil, Inorg. Chem., 2011, 50, 9153.

5 I. Nemec, M. Machata, R. Herchel, R. Boča and Z. Trávníček, Dalton Trans., 2012, 41, 14603.

6 (a) E. Pardo, M. Verdaguer, P. Herson, H. Rousseliere, J. Cano, M. Julve, F. Lloret and R. Lescouezec, Inorg. Chem., 2011, 50, 6250; (b) I. Nemec, R. Herchel, I. Šalitroš, Z. Trávníček, J. Moncol', H. Fuess, M. Ruben and W. Linert, CrystEngComm, 2012, 14, 7015; (c) M. Korabik, Z. Repická, L. Martiška, J. Moncol, J. Švorec, Z. Padělková, T. Lis, M. Mazúr and D. Valigura, Z. Anorg. Allg. Chem., 2011, 637, 224; (d) D. Valigura, J. Moncol, M. Korabik, Z. Pučekova, T. Lis, J. Mrozinski and M. Melnik, Eur. J. Inorg. Chem., 2006, 3813; (e) Z. Vasková, J. Moncol', M. Korábik, D. Valigura, J. Švorec, T. Lis, M. Valko and M. Melník, Polyhedron, 2010, 29, 154-163; (f) B. Kozlevčar, N. Kitanovski, Z. Jagličić, N. A. G. Bandeira, V. Robert, B. Le Guennic and P. Gamez, Inorg. Chem., 2012, 51(5), 3094-3102; (g) J. S. Costa, N. A. G. Bandeira, B. Le Guennic, V. Robert, P. Gamez, G. Chastanet, L. Ortiz-Frade and L. Gasque, Inorg. Chem., 2011, 50(12), 5696-5705; (h) J. Tang, J. S. Costa, A. Golobič, B. Kozlevčar, A. Robertazzi, A. V. Vargiu, P. Gamez and J. Reedijk, Inorg. Chem., 2009, 48(12), 5473-5479.

7 H. J. Buser, D. Schwarzenbach, W. Petter and A. Ludi, Inorg. Chem., 1977, 16, 2704.

8 R. Lescouëzec, L. M. Toma, J. Vaissermann, M. Verdaguer, F. S. Delgado, C. Ruiz-Pérez, F. Lloret and M. Julve, Coord. Chem. Rev., 2005, 249, 2691.

9 (a) R. Ishikawa, R. Miyamoto, H. Nojiri, B. K. Breedlove and M. Yamashita, Inorg. Chem., 2013, 52(15), 8300-8302; (b) H. Kara, A. Azizoglu, A. Karaoglu, Y. Yahsi, E. Gungor, A. Caneschi and L. Sorace, CrystEngComm, 2012, 14, 73207329; (c) H. Miyasaka, T. Madanbashi, A. Saitoh, N. Motokawa, R. Ishikawa, M. Yamashita, S. Bahr, W. Wernsdorfer and R. Clerac, Chem. - Eur. J., 2012, 18, 3942-3954; (d) X. Shen, Q. Zhang, H. Zhou, H. Zhou and A. Yuan, New J. Chem., 2012, 36, 1180-1186; (e) E. Colacio, M. Ghazi, H. Stoeckli-Evans, F. Lloret, J. M. Moreno and C. Perez, Inorg. Chem., 2001, 40, 4876; $(f)$ H. Z. Kou, J. K. Tang, D. Z. Liao, S. Gao, P. Cheng, Z. H. Jiang, S. P. Yan, G. L. Wang, B. Chansou and J. P. Tuchagues, Inorg. Chem., 2001, 40, 4839; (g) J. Larionova, M. Gross, M. Pilkington, H. Andres, H. Stoeckli-Evans, H. U. Gudel and S. Decurtins, Angew. Chem., Int. Ed., 2000, 39, 1605; (h) M. Ohba, N. Usuki, N. Fukita and H. Okawa, Angew. Chem., Int. Ed., 1999, 38, 1795; (i) Z. J. Zhong, H. Seino, Y. Mizobe, M. Hidai, A. Fujishima, S. Ohkoshi and
K. Hashimoto, J. Am. Chem. Soc., 2000, 122, 2952; (j) A. Marvilliers, S. Parsons, E. Riviere, J. P. Audiere, M. Kurmoo and T. Mallah, Eur. J. Inorg. Chem., 2001, 1287.

10 (a) M. Ohba and H. Okawa, Coord. Chem. Rev., 2000, 198, 313; (b) M. Verdaguer, A. Bleuzen, V. Marvaud, J. Vaissermann, M. Seuleiman, C. Desplanches, A. Scuiller, C. Train, R. Garde, G. Gelly, C. Lomenech, I. Rosenman, P. Veillet, C. Cartier and F. Villain, Coord. Chem. Rev., 1999, 190, 1023; (c) W. P. Fehlhammer and M. Fritz, Chem. Rev., 1993, 93, 1243; (d) K. R. Dunbar and R. A. Heintz, Prog. Inorg. Chem., 1997, 45, 283; (e) S. M. Holmes and G. S. Girolami, J. Am. Chem. Soc., 1999, 121, 5593; (f) L. G. Beauvais and J. R. Long, J. Am. Chem. Soc., 2002, 124, 12096; ( $g$ ) O. Sato, T. Iyoda, A. Fujishima and K. Hashimoto, Science, 1996, 272, 704; $(h)$ T. D. Harris, H. S. Soo, C. J. Chang and J. R. Long, Inorg. Chim. Acta, 2011, 369, 91.

11 (a) H. J. Choi, J. J. Sokol and J. R. Long, Inorg. Chem., 2004, 43, 1606; (b) P. Przychodze, M. Rams, C. Guyard-Duhayon and B. Sieklucka, Inorg. Chem. Commun., 2005, 8, 350; (c) M. Ferbinteanu, H. Miyasaka, W. Wernsdorfer, K. Nakata, K. Sugiura, M. Yamashita, C. Coulon and R. Clerac, J. Am. Chem. Soc., 2005, 127, 3090; (d) H. S. Yoo, H. H. Ko, D. W. Ryu, J. W. Lee, J. H. Yoon, W. R. Lee, H. C. Kim, E. K. Koh and C. S. Hong, Inorg. Chem., 2009, 48, 5617; (e) H. Y. Kou, Y. N. Ni, B. C. Zhou and R. J. Wang, Inorg. Chem. Commun., 2004, 7, 1150; (f) F. Tuyčras, A. Schiller, C. Duhayon, M. Hernandez-Molina, F. F. de Biani, M. Verdaguer, T. Mallah, W. Wernsdorfer and V. Marvaud, Inorg. Chim. Acta, 2008, 361, 3505; (g) M. Atanasov, C. Busche, P. Comba, F. E. Hallak, B. Martin, G. Rajaraman, J. van Slageren and H. Wadepohl, Inorg. Chem., 2008, 47, 8112.

$12 \mathrm{H}_{2} \mathrm{~L} 4 \mathrm{a}=N, N^{\prime}$-cyclohexane-bis(salicylideneiminate), $\mathrm{H}_{2} \mathrm{~L} 4 \mathrm{~b}=$ $N, N^{\prime}$-benzene-bis(salicylideneiminate), $\mathrm{H}_{2} \mathrm{~L} 4 \mathrm{c}=N, N^{\prime}$-ethylene-bis(3-ethoxysalicylideneiminate), $\quad \mathrm{H}_{2} \mathrm{~L} 4 \mathrm{~d}=N, N^{\prime}-1$ methylethylene-bis(3-ethoxysalicylideneiminate), $\mathrm{H}_{2} \mathrm{~L} 4 \mathrm{e}=$ $N, N^{\prime}$-benzene-bis(naphthylideneiminate), $\mathrm{H}_{2} \mathrm{~L} 4 \mathrm{f}=N, N^{\prime}$ ethylene-bis(salicylideneiminate), $\mathrm{H}_{2} \mathrm{~L} 4 \mathrm{~g}=N, N^{\prime}$-1-methylethylene-bis(salicylideneiminate), $\mathrm{H}_{2} \mathrm{~L} 4 \mathrm{~h}=N, N^{\prime}$-1,1,2,2-tetramethyl ethylene-bis(salicylideneiminate), $\mathrm{H}_{2} \mathrm{~L} 4 \mathrm{i}=N, N^{\prime}-$ ethylene-bis(3-methoxysalicylideneiminate), $\mathrm{H}_{2} \mathrm{~L} 4 \mathrm{j}=N, N^{\prime}-$ ethylene-bis(5-bromosalicylideneiminate), $\mathrm{H}_{2} \mathrm{~L} 4 \mathrm{k}=N, N^{\prime}-$ 1,3-propylene-bis(5-bromosalicylideneiminate), $\mathrm{H}_{2} \mathrm{~L} 4 \mathrm{l}=$ $N, N^{\prime}$-1,3-propylene-bis(3-methoxysalicylideneiminate), $\mathrm{H}_{2} \mathrm{~L} 4 \mathrm{~m}=N, N^{\prime}$-1,1,2,2-tetramethylethylene-bis(naphthylideneiminate), $\mathrm{H}_{2} \mathrm{~L} 4 \mathrm{n}=N, N^{\prime}$-benzene-bis(4-aminodiethylenesalicylideneiminate), $\mathrm{H}_{2} \mathrm{~L} 4 \mathrm{o}=N, N^{\prime}$-3-methylbenzene-bis(3ethoxysalicylideneiminate) and $\mathrm{H}_{2} \mathrm{~L} 4 \mathrm{p}=N, N^{\prime}$-ethylene-bis(salicylidenebenzeneiminate).

13 (a) R. Dreos, G. Nardin, L. Randaccio, P. Siega, G. Tauzher and V. Vrdoljak, Inorg. Chim. Acta, 2003, 349, 239; (b) R. Blaauw, J. L. van der Baan, S. Balt, M. W. G. de Bolster, G. W. Klumpp, H. Kooijman and A. L. Spek, Chem. Commun., 1998, 1295; (c) B. C. Wang, B. T. Huie and W. P. Schaefer, Acta Crystallogr., Sect. B: Struct. Crystallogr. Cryst. Chem., 1979, 35, 1232; (d) R. Dreos, G. Nardin, 
L. Randaccio, P. Siega, G. Tauzher and V. Vrdoljak, Inorg. Chem., 2003, 42, 6805; (e) R. Blaauw, I. E. Kingma, J. H. Laan, J. L. van der Baan, S. Balt, M. W. G. de Bolster, G. W. Klumpp, W. J. J. Smeets and A. L. Spek, J. Chem. Soc., Perkin Trans. 1, 2000, 1199; (f) J. Welby, L. N. Rusere, J. M. Tanski and L. A. Tyler, Inorg. Chim. Acta, 2009, 362, 1405; $(g)$ S. Bruckner, M. Calligaris, G. Nardin and L. Randaccio, Acta Crystallogr., Sect. B: Struct. Crystallogr. Cryst. Chem., 1969, 25, 1671.

14 (a) A. Geiss and H. Vahrenkamp, Eur. J. Inorg. Chem., 1999, 1793; (b) C. H. Yang, J. A. Ladd and V. L. Goedken, J. Coord. Chem., 1988, 19, 235; (c) M. Gerloch and F. E. Mabbs, J. Chem. Soc. A, 1967, 1900; (d) J. L. Resce, J. C. Fanning, C. S. Day, S. J. Uhm, A. F. Croisy and L. K. Keefer, Acta Crystallogr., Sect. C: Cryst. Struct. Commun., 1987, 43, 2100; (e) E. Evangelio, N. P. Rath and L. M. Mirica, Dalton Trans., 2000, 41, 8010.

15 C. Y. Wong, W. L. Man, C. Wang, H. L. Kwong, W. Y. Wong and T. C. Lau, Organometallics, 2008, 27, 324.

16 J. M. McInnes, D. Swallow, A. J. Blake and P. Mountford, Inorg. Chem., 1998, 37, 5970.

17 (a) M. Odoko, N. Tsuchida and N. Okabe, Acta Crystallogr., Sect. E: Struct. Rep. Online, 2006, 62, m708; (b) N. Meyer and P. W. Roesky, Z. Anorg. Allg. Chem., 2007, 633, 2292; (c) H. Kooijman, A. L. Spek, M. Kuil and P. W. N. M. van Leeuwen, private communication, 2011.

18 (a) R. J. Tao, C. Z. Mei, B. T. Liu and J. Y. Niu, Chin. J. Chem., 2006, 24, 1559; (b) M. M. Bhadbhade and D. Srinivas, Inorg. Chem., 1993, 32, 6122.

19 Y. Ding, Z. Ku, L. Wang, Y. Hu and Y. Zhou, Acta Crystallogr., Sect. E: Struct. Rep. Online, 2008, 64, m173.

20 I. Nemec, T. Šilha, R. Herchel and Z. Trávníček, Eur. J. Inorg. Chem., 2013, 5781.

21 T. Šilha, I. Nemec, R. Herchel and Z. Trávníček, CrystEngComm, 2013, 15, 5351.

22 M. Clemente-León, E. Coronado, J. R. Galán-Mascarós, C. J. Gómez-García, T. Woike and J. M. Clemente-Juan, Inorg. Chem., 2001, 40, 87.

23 (a) C. Yang, Q. Wang, Y. Ma, G. Tang, D. Liao, S. Yan, G. Yang and P. Cheby, Inorg. Chem., 2010, 49, 2047; (b) H. Shu, Y. Xu and X. Shen, J. Chem. Crystallogr., 2011, 41, 1218.

24 R. Ababei, Y. Li, O. Roubeau, M. Kalisz, N. Bréfuel, C. Coulon, E. Harté, X. Liu, C. Mathoniére and R. Clérac, New J. Chem., 2009, 33, 1237.

25 T. Wang, J. Xie, C. Xia, Y. Wu, J. Jing and J. Huaxue, Chin. J. Struct. Chem., 2010, 29, 1265.

26 M. Clemente-León, E. Coronado, J. R. Galán-Mascarós, C. J. Gómez-García, Th. Woike and J. M. Clemente-Juan, Inorg. Chem., 2001, 40, 87.

27 A. Yuan, L. Lu, X. Shen and K. Yu, Transition Met. Chem., 2003, 28, 163.

28 X. Shen, Z. Xu, A. Juan and Z. Huang, Transition Met. Chem., 2004, 29, 100.

29 (a) N. A. G. Bandeira and B. Le Guennic, J. Phys. Chem. A, 2012, 116, 3465; (b) C. Desplanches, E. Ruiz, A. Rodriguez-
Fortea and S. Alvarez, J. Am. Chem. Soc., 2002, 124, 5197; (c) B. Le Guennic, N. Ben Amor, D. Maynau and V. Robert, J. Chem. Theory Comput., 2009, 5, 1506.

30 R. Pritchard, S. A. Barrett, C. A. Kilner and M. A. Halcrow, Dalton Trans., 2008, 3159.

31 K. Nakamoto, Infrared and Raman Spectra of Inorganic and Coordination Compounds, Part B: Applications in Coordination, Organometalic and Bioinorganic Chemistry, Wiley, New York, 5th edn, 1997.

32 The standard deviations were calculated as $\sigma_{i}=\left(P_{i i}{ }^{-1} \cdot S /(N-\right.$ $k))^{-1 / 2}$, where $P_{i j}=\sum\left(\delta \mu_{n} / \delta a_{i} \cdot \delta \mu_{n} / \delta a_{j}\right)$ and $S=\sum\left(\mu_{n}-\mu_{n}{ }^{\exp }\right)^{2}$ with $n=1$ to $N ; a_{i}$ and $a_{j}$ are fitted parameters, $N$ is number of experimental points (sum of temperature and field dependent data), $\mu_{n}$ and $\mu_{n}^{\exp }$ are the calculated and experimental effective magnetic moments for a given temperature and magnetic field. The $\sigma_{i}$ was then multiplied by Student's $t_{95 \%}$ to provide confidence limits with $95 \%$ probabilities listed in text.

33 R. Boča, Coord. Chem. Rev., 2004, 248, 757.

34 CrysAlis CCD and CrysAlis RED, Version 1.171.33.52, Oxford Diffraction Ltd, England, 2009.

35 G. M. Sheldrick, Acta Crystallogr., Sect. A: Fundam. Crystallogr., 2008, 64, 112.

36 (a) F. Neese, WIREs Comput. Mol. Sci., 2012, 2, 73; (b) C. Lee, W. Yang and R. G. Parr, Phys. Rev. B: Condens. Matter, 1988, 37, 785; (c) A. D. Becke, J. Chem. Phys., 1993, 98, 1372; (d) A. D. Becke, J. Chem. Phys., 1993, 98, 5648; (e) P. J. Stephens, F. J. Devlin, C. F. Chabalowski and M. J. Frisch, J. Phys. Chem., 1994, 98, 11623.

37 (a) E. Ruiz, J. Cano, S. Alvarez and P. Alemany, J. Comput. Chem., 1999, 20, 1391; (b) E. Ruiz, A. Rodríguez-Fortea, J. Cano, S. Alvarez and P. Alemany, J. Comput. Chem., 2003, 24, 982 .

38 (a) K. Yamaguchi, Y. Takahara and T. Fueno, in Applied Quantum Chemistry, ed. V. H. Smith, Reidel, Dordrecht, 1986, p. 155; (b) T. Soda, Y. Kitagawa, T. Onishi, Y. Takano, Y. Shigeta, H. Nagao, Y. Yoshioka and K. Yamaguchi, Chem. Phys. Lett., 2000, 319, 223.

39 (a) A. Schaefer, H. Horn and R. Ahlrichs, J. Chem. Phys., 1992, 97, 2571; (b) A. Schafer, C. Huber and R. J. Ahlrichs, Chem. Phys., 1994, 100, 5829; (c) F. Weigend and R. Ahlrichs, Chem. Phys., 2005, 7, 3297.

40 A. Pantazis, X. Y. Chen, C. R. Landis and F. Neese, J. Chem. Theory Comput., 2008, 4, 908.

41 (a) F. Neese, F. Wennmohs, A. Hansen and U. Becker, Chem. Phys., 2009, 356, 98; (b) R. Izsak and F. Neese, J. Chem. Phys., 2011, 135, 144105.

42 (a) A. D. Becke, Phys. Rev. A, 1988, 38, 3098; (b) J. P. Perdew, Phys. Rev. B: Condens. Matter, 1986, 33, 8822; (c) J. P. Perdew, Phys. Rev. B: Condens. Matter, 1986, 34, 7406.

43 S. Sinnecker, A. Rajendran, A. Klamt, M. Diedenhofen and F. Neese, J. Phys. Chem. A, 2006, 110, 2235.

44 (a) S. Grimme, J. Comput. Chem., 2004, 25, 1463; (b) S. Grimme, J. Comput. Chem., 2006, 27, 1787; (c) S. Grimme, J. Antony, S. Ehrlich and H. Krieg, J. Chem. Phys., 2010, 132, 154104. 